\title{
Evaluating the performance of commonly used gas analysers for methane eddy covariance flux measurements: the InGOS inter-comparison field experiment
}

\author{
O. Peltola ${ }^{1}$, A. Hensen ${ }^{2}$, C. Helfter ${ }^{3}$, L. Belelli Marchesini ${ }^{4}$, F. C. Bosveld ${ }^{5}$, W. C. M. van den Bulk ${ }^{2}$, J. A. Elbers ${ }^{6}$, \\ S. Haapanala ${ }^{1}$, J. Holst ${ }^{7}$, T. Laurila ${ }^{8}$, A. Lindroth ${ }^{7}$, E. Nemitz ${ }^{3}$, T. Röckmann ${ }^{9}$, A. T. Vermeulen ${ }^{2}$, and I. Mammarella ${ }^{1}$ \\ ${ }^{1}$ Department of Physics, University of Helsinki, Helsinki, Finland \\ ${ }^{2}$ Energy Research Centre of the Netherlands, Petten, the Netherlands \\ ${ }^{3}$ Centre for Ecology and Hydrology, Edinburgh research station, Penicuik, UK \\ ${ }^{4}$ Department of Earth Sciences, VU University, Amsterdam, the Netherlands \\ ${ }^{5}$ Royal Netherlands Meteorological Institute, De Bilt, the Netherlands \\ ${ }^{6}$ Alterra, Wageningen, the Netherlands \\ ${ }^{7}$ Department of Physical Geography and Ecosystem Science, Lund University, Lund, Sweden \\ ${ }^{8}$ Finnish Meteorological Institute, Helsinki, Finland \\ ${ }^{9}$ Institute for Marine and Atmospheric Research Utrecht, Utrecht University, Utrecht, the Netherlands
}

Correspondence to: O. Peltola (olli.peltola@helsinki.fi)

Received: 20 December 2013 - Published in Biogeosciences Discuss.: 13 January 2014

Revised: 30 April 2014 - Accepted: 5 May 2014 - Published: 17 June 2014

\begin{abstract}
The performance of eight fast-response methane $\left(\mathrm{CH}_{4}\right)$ gas analysers suitable for eddy covariance flux measurements were tested at a grassland site near the Cabauw tall tower (Netherlands) during June 2012. The instruments were positioned close to each other in order to minimise the effect of varying turbulent conditions. The moderate $\mathrm{CH}_{4}$ fluxes observed at the location, of the order of $25 \mathrm{nmol} \mathrm{m}^{-2} \mathrm{~s}^{-1}$, provided a suitable signal for testing the instruments' performance.

Generally, all analysers tested were able to quantify the concentration fluctuations at the frequency range relevant for turbulent exchange and were able to deliver high-quality data. The tested cavity ringdown spectrometer (CRDS) instruments from Picarro, models G2311-f and G1301-f, were superior to other $\mathrm{CH}_{4}$ analysers with respect to instrumental noise. As an open-path instrument susceptible to the effects of rain, the LI-COR LI-7700 achieved lower data coverage and also required larger density corrections; however, the system is especially useful for remote sites that are restricted in power availability. In this study the open-path LI-7700 results were compromised due to a data acquisition problem in our data-logging setup. Some of the older closed-path anal-
\end{abstract}

ysers tested do not measure $\mathrm{H}_{2} \mathrm{O}$ concentrations alongside $\mathrm{CH}_{4}$ (i.e. FMA1 and DLT-100 by Los Gatos Research) and this complicates data processing since the required corrections for dilution and spectroscopic interactions have to be based on external information. To overcome this issue, we used $\mathrm{H}_{2} \mathrm{O}$ mole fractions measured by other gas analysers, adjusted them with different methods and then applied them to correct the $\mathrm{CH}_{4}$ fluxes. Following this procedure we estimated a bias of the order of $0.1 \mathrm{~g}\left(\mathrm{CH}_{4}\right) \mathrm{m}^{-2}(8 \%$ of the measured mean flux) in the processed and corrected $\mathrm{CH}_{4}$ fluxes on a monthly scale due to missing $\mathrm{H}_{2} \mathrm{O}$ concentration measurements. Finally, cumulative $\mathrm{CH}_{4}$ fluxes over 14 days from three closed-path gas analysers, G2311-f (Picarro Inc.), FGGA (Los Gatos Research) and FMA2 (Los Gatos Research), which were measuring $\mathrm{H}_{2} \mathrm{O}$ concentrations in addition to $\mathrm{CH}_{4}$, agreed within $3 \%\left(355-367 \mathrm{mg}\left(\mathrm{CH}_{4}\right) \mathrm{m}^{-2}\right)$ and were not clearly different from each other, whereas the other instruments derived total fluxes which showed small but distinct differences $\left( \pm 10 \%, 330-399 \mathrm{mg}\left(\mathrm{CH}_{4}\right) \mathrm{m}^{-2}\right)$. 


\section{Introduction}

Methane $\left(\mathrm{CH}_{4}\right)$ is the third most important greenhouse gas for the radiative balance of the atmosphere, after water $\left(\mathrm{H}_{2} \mathrm{O}\right)$ and carbon dioxide $\left(\mathrm{CO}_{2}\right)$. Due to its high global warming potential of 28 (at the 100-year horizon), changes in its abundance have an effect on the ongoing climate change (Myhre et al., 2013). The total global $\mathrm{CH}_{4}$ source is thought to be relatively well quantified, but the relative contributions of each source and changes in individual sources are not (Ciais et al., 2013). The gradual increase in atmospheric $\mathrm{CH}_{4}$ concentration observed over the last century decreased in the past decades and came to a standstill around 2000 for several years before starting to increase again from 2007 (Dlugokencky et al., 2011). Explanations for the temporary standstill are inconsistent with each other, highlighting the need for improved bottom-up studies to understand better the most important factors controlling the changes in atmospheric $\mathrm{CH}_{4}$ (Heimann, 2011; Nisbet et al., 2014). Several mechanisms have been proposed to explain the temporary decline in the growth rate, such as (a) decreases in anthropogenic emissions (e.g. Dlugokencky et al., 1994), (b) decreases in anthropogenic emissions before 1999, and decreases in wetland emissions after that (Bousquet et al., 2006) or (c) changes in the removal rate by $\mathrm{OH}$ (e.g. Monteil et al., 2011). A network of eddy covariance (EC) towers can provide direct and continuous monitoring of ecosystem scale surface fluxes that can be upscaled to landscape and continental scales using process-based models. This combined approach can help unravel the relative contribution of different sources and sinks to the global $\mathrm{CH}_{4}$ budget.

Over the last 20 years, with the advances made in laser absorption spectroscopy (LAS), several $\mathrm{CH}_{4}$ gas analysers suitable for eddy covariance measurements have been developed. Field applications of the first generation of $\mathrm{CH}_{4} \mathrm{EC}$ analysers were limited due to the need for cooling lasers and/or detectors for cryogenic temperatures, and they also had relatively high flux detection limits (e.g. Fowler et al., 1995). This made long-term measurements challenging and timeconsuming and inhibited measurements at remote locations which are often important $\mathrm{CH}_{4}$ sources, such as remote wetlands that are distributed across the globe (e.g. Siberia, South America, the tropics). After the development of gas analysers that can use Peltier cooling systems, measurements became possible at these remote locations, although the availability of mains power remained an issue. Recently, a new generation of commercial fast-response $\mathrm{CH}_{4}$ sensors has become available, which offers a much improved signal/noise ratio and is even easier to use due to stable operation. Consequently there are large efforts to create continental-scale networks of measurement stations (e.g. the Integrated Carbon Observation System (ICOS) and the Integrated non- $\mathrm{CO}_{2}$ Greenhouse gas Observing System (InGOS)) allowing for $\mathrm{CH}_{4}$ fluxes to be measured continuously. In this context, it is important to characterise the currently available $\mathrm{CH}_{4}$ analy- sers and to assess their performance. A few inter-comparison studies exist (Detto et al., 2011; Peltola et al., 2013; Tuzson et al., 2010), but none of them included such a wide range of models currently available on the market as this study.

This study reports results from an inter-comparison experiment held at a Dutch grassland site in June 2012 as part of the InGOS EU-FP7 project. The objective of this study was to evaluate the field performance of the instruments tested, to determine the accuracy and precision of the measured fluxes and to assess the relative merits of different instrumental designs (e.g. open- vs. closed-path gas analysers). Due to its relatively short duration, our study cannot answer the question of how applicable the tested instruments are for longterm field usage; for that the reader is referred to Peltola et al. (2013) and Detto et al. (2011). This presentation of the results addresses the following topics in detail: (i) precision of $\mathrm{CH}_{4}$ measurements from each instrument; (ii) an analysis of the impact of corrections due to density fluctuations (WPL) and spectroscopic effects on the fluxes; (iii) an evaluation of the errors arising when an external $\mathrm{H}_{2} \mathrm{O}$ signal is used for the WPL and spectroscopic corrections of the $\mathrm{CH}_{4}$ flux and (iv) the consistency in total accumulated $\mathrm{CH}_{4}$ emissions during a 14-day period. For this effect, eight $\mathrm{CH}_{4}$ gas analysers, including models by Picarro Inc., Los Gatos Research, LICOR Biogeosciences and Aerodyne Research Inc., were set up to measure side-by-side for 22 days.

\section{Experimental setup}

\subsection{Site}

The gas analyser inter-comparison experiment was performed at the Cabauw Experimental Site for Atmospheric Research (CESAR) (51 $51^{\circ} 12.00^{\prime \prime} \mathrm{N}, 4^{\circ} 55^{\prime} 34.48^{\prime \prime} \mathrm{E}$, $-0.7 \mathrm{~m}$ a.s.l). The Cabauw tall tower combines a comprehensive set of observations to profile many aspects of the atmospheric column (www.cesar-observatory.nl). A broad range of atmospheric and ecological measurements are conducted on a continuous basis. The site is located in an agricultural landscape, with $\mathrm{CH}_{4}$ emissions originating from ruminants and other agricultural activities, but also from the peaty soil and the drainage ditches between the surrounding fields. The soil consists of a 0.5 to $1 \mathrm{~m}$ deep clay layer on top of a peat layer which is several metres deep. The water table level is on average $0.5 \mathrm{~m}$ below the surface. For a more thorough site description, see e.g. Beljaars and Bosveld (1997) and van Ulden and Wieringa (1996).

During the campaign, the vegetation, which consisted of grass and occasional sedges next to the drainage ditches surrounding the measurement tower, was low $(0.05-0.2 \mathrm{~m})$, although a taller maize field was located $70 \mathrm{~m}$ away in the SW-W direction from the measurement mast (see Fig. 1). The landscape is relatively flat and level, making the area ideal for micro-meteorological flux measurements. The eddy 


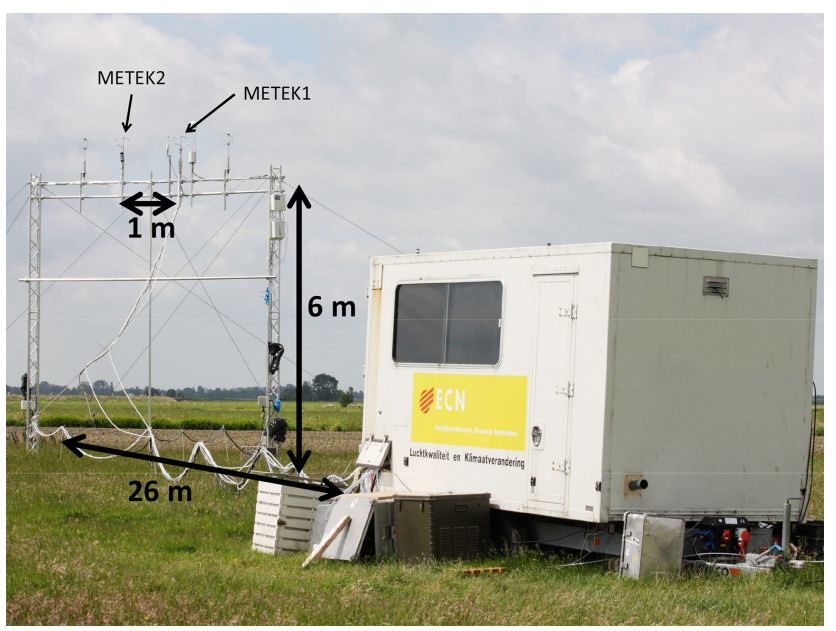

Figure 1. Picture of the measurement setup. The picture was taken towards the most common wind direction during the campaign. The trailer which housed the closed-path instruments and data-logging computer is at the front of the picture.

covariance measurement tower was approximately $87 \mathrm{~m}$ away from the nearest building, the Cabauw tall tower (height $213 \mathrm{~m}$ ) located to the NE. The fetch in the main wind direction (W-SW) was free from any large obstacles for several hundreds of metres.

Meteorological conditions during the campaign were recorded next to the measurement mast by a weather station operated by the Royal Netherlands Meteorological Institute (KNMI). Air temperatures during the campaign ranged between 4.3 and $22.0^{\circ} \mathrm{C}$ with an average of $14.9^{\circ} \mathrm{C}$. Rain was recorded on 19 out of 22 measurement days, 21 June being the rainiest day with a total of $14.1 \mathrm{~mm}$ of rain. Cumulative rainfall during the whole campaign was $63.1 \mathrm{~mm}$, which is close to the climatological mean for the site for this period. Relative humidity ranged between 43 and $100 \%$, with an average of $78 \%$. The campaign was thus held in relatively cool and moist conditions.

\subsection{Measurement system}

Eddy covariance flux measurements were conducted between 6 and 27 June 2012 at a $6.5 \mathrm{~m}$ high tower. Two sonic anemometers were used (both USA-1, METEK, Germany) to acquire fast measurements of wind velocity components and sonic temperature. Similar instruments were used in an effort to minimise the potential systematic bias on $\mathrm{CH}_{4}$ fluxes caused by the use of different types of anemometers. The anemometers were placed on the same tower at the same height with approximately one metre horizontal distance in the NW-SE direction between them (see Fig. 1).

All data were logged at a frequency of $20 \mathrm{~Hz}$ by a central computer located in a trailer that also housed the closed-path analysers. The trailer was approximately $26 \mathrm{~m}$ away from the measurement tower in the NE direction. The trailer was air conditioned and the indoor temperature was kept around $22^{\circ} \mathrm{C}$. Data-logging software capable of handling and saving all 56 variables at $20 \mathrm{~Hz}$ was written in LabView for this campaign (National Instruments, USA). Actual sampling frequencies for the sonic anemometers were $20 \mathrm{~Hz}$ and for the gas analysers they are given in Table 1.

The gas analysers were divided between the two anemometers, which will from now on be referred to as METEK1 and METEK2. Two open-path analysers (models LI-7500 and LI-7700, LI-COR Biogeosciences, USA) were situated on both sides of METEK1, displaced in the NW$\mathrm{SE}$ direction by approximately $0.3 \mathrm{~m}$. The LI-7500 measured $\mathrm{CO}_{2}$ and $\mathrm{H}_{2} \mathrm{O}$ mole densities, while the LI-7700 measured $\mathrm{CH}_{4}$. Two different LI-7700 analysers were used sequentially and the switch between instruments was done on 19 June. The LI-7700 is a low-power, lightweight $\mathrm{CH}_{4}$ gas analyser with a $0.8 \mathrm{~m}$ long open measurement cell. Its operation principle is based on laser absorption spectroscopy, more precisely wavelength modulation spectroscopy (McDermitt et al., 2010). The LI-7700 reports $\mathrm{CH}_{4}$ molar density $\left(\mathrm{mmol} \mathrm{m}{ }^{-3}\right)$ while all the other $\mathrm{CH}_{4}$ analysers report mole fraction $\left(\mu \mathrm{mol} \mathrm{mol}{ }^{-1}\right)$. Unfortunately, the data were recorded with three decimals (e.g. $0.088 \mathrm{mmol} \mathrm{m}^{-3}$ ), and thus the resolution of the LI-7700 data was limited to $0.001 \mathrm{mmol} \mathrm{m}^{-3}$ (about $20 \mathrm{ppb}$ ); for the other instruments a resolution of $0.001 \mathrm{ppm}$ was used. Because of this oversight, the $\mathrm{CH}_{4}$ fluxes from the LI-7700 instrument were more attenuated and noisier than normal (cf. Fig. 5a below). This data-logging problem should be kept in mind for the interpretation of the results of this study.

In addition to the two open-path devices, three closedpath gas analysers (G2311-f, Picarro Inc., USA; FGGA, Los Gatos Research, USA; DLT-100, Los Gatos Research, USA) sampled air close to METEK1 (the sampling setup of all gas analysers is described in Table 1). The G2311-f is a new gas analyser by Picarro Inc. and is based on cavity ringdown spectroscopy (CRDS). The analyser is able to make simultaneous fast measurements of $\mathrm{CO}_{2}, \mathrm{CH}_{4}$ and $\mathrm{H}_{2} \mathrm{O}$ mole fractions. The whole sampling line connected to the G2311-f was heated in order to prevent condensation of $\mathrm{H}_{2} \mathrm{O}$ on the tube walls. The FGGA ("Fast Greenhouse Gas Analyzer") developed by Los Gatos Research is based on off-axis integrated cavity output spectroscopy (OA-ICOS) and the instruments provide fast measurements of $\mathrm{CO}_{2}, \mathrm{CH}_{4}$ and $\mathrm{H}_{2} \mathrm{O}$ mole fractions on a continuous basis. The FGGA tested is the standard (rackmount) version rather than the enhanced performance version introduced later with more accurate temperature control. The third closed-path analyser accompanying METEK1 was a DLT-100, an older benchtop model (production year: 2005) by Los Gatos Research. It is based on the same measurement principle as the FGGA (OA-ICOS); however, it is able to measure and report mole fractions only of $\mathrm{CH}_{4}$. Accidentally, until 16 June the instrument reported data at $1 \mathrm{~Hz}$, and after that the sampling frequency of this instrument was set to $10 \mathrm{~Hz}$. This was taken into account 


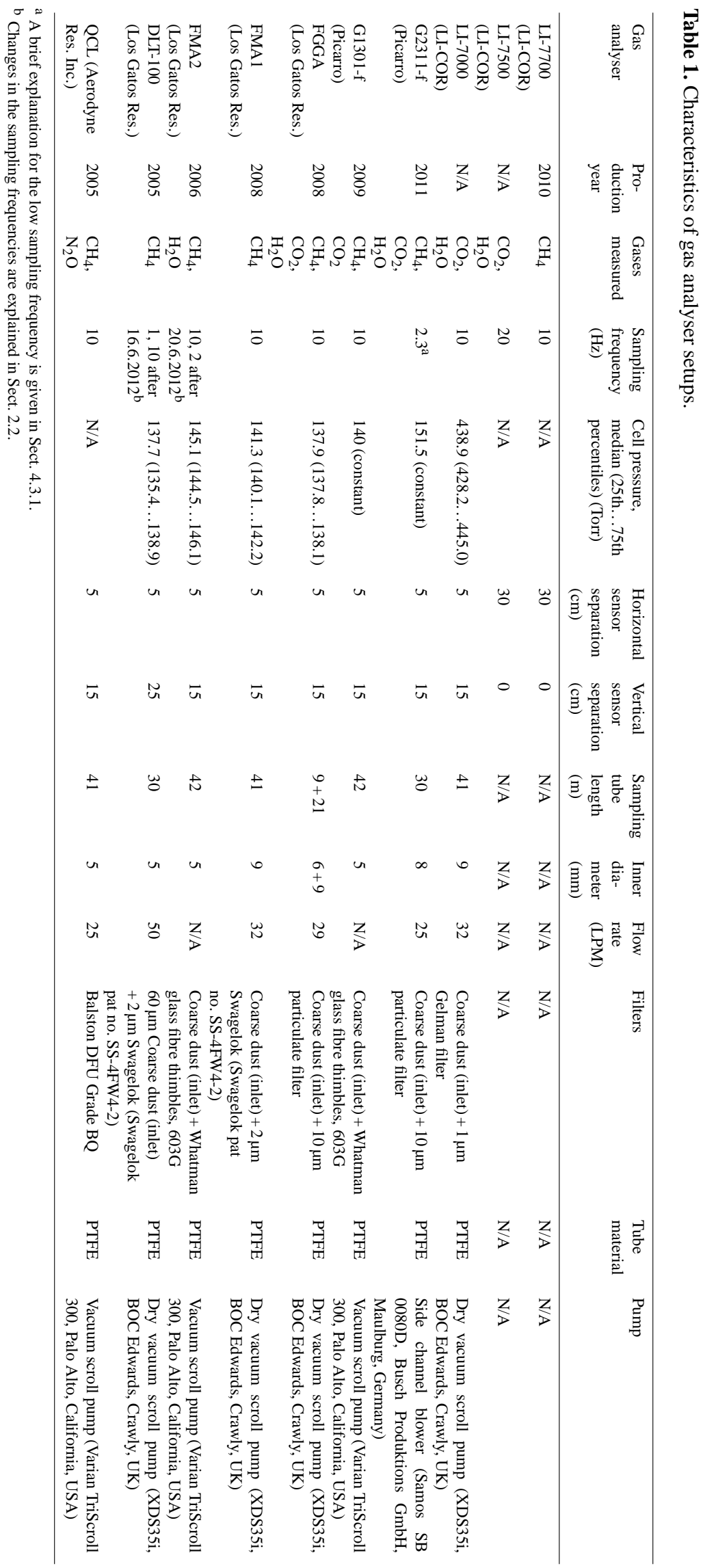


when spectral corrections were applied (Sect. 4.3.1). The cell pressure of DLT-100 varied slightly during the campaign, whereas FGGA had a relatively constant cell pressure throughout the measurement period (Table 1). Picarro instruments control cavity pressure rigorously by opening/closing valves in front of or behind the cavity, which keeps the cavity pressure practically constant.

Air for five closed-path gas analysers was sampled from near METEK2. Four of them measured $\mathrm{CH}_{4}$ and one only $\mathrm{CO}_{2}$ and $\mathrm{H}_{2} \mathrm{O}$. These four $\mathrm{CH}_{4}$ analysers were a G1301-f (Picarro Inc., USA), a QCL (Aerodyne Research Inc., USA) and two FMAs (Los Gatos Research, USA). Henceforth, the two rackmount FMAs are referred to as FMA1 and FMA2. FMA2 was taken back to the laboratory for cleaning in the middle of the campaign (between 19 and 20 June) and after the cleaning operation the instrument measured by accident only with $2 \mathrm{~Hz}$ until the end of the campaign. G1301-f is an older model by Picarro Inc. The measurement principle is the same as in G2311-f and the instrument is capable of measuring any two out of three gases $\left(\mathrm{CH}_{4}, \mathrm{CO}_{2}\right.$ and $\left.\mathrm{H}_{2} \mathrm{O}\right)$ simultaneously. During this campaign the instrument was not able to measure $\mathrm{H}_{2} \mathrm{O}$ and thus $\mathrm{CH}_{4}$ and $\mathrm{CO}_{2}$ were selected. The QCL is an older (pulsed) quantum cascade laser by Aerodyne Research Inc. The detector was cooled with liquid nitrogen using an automated $\mathrm{LN}_{2}$ filling system. During this campaign, the QCL measured both $\mathrm{CH}_{4}$ and $\mathrm{N}_{2} \mathrm{O}$. A Perma Pure drier was connected to the QCL sampling line in order to remove $\mathrm{H}_{2} \mathrm{O}$ from the air samples. The Fast Methane Analyzer (FMA) is a slightly older model by Los Gatos Research using OA-ICOS. The standard FMA instrument is able to measure and report only $\mathrm{CH}_{4}$ mole fractions, but it can be updated to measure also $\mathrm{H}_{2} \mathrm{O}$. While FMA1 was a standard $\mathrm{CH}_{4}$ instrument, FMA2 was upgraded to enable the parallel $\mathrm{H}_{2} \mathrm{O}$ measurements. The LI-7000 (LI-COR Biogeosciences, USA) was used to measure $\mathrm{CO}_{2}$ and $\mathrm{H}_{2} \mathrm{O}$ from the vicinity of METEK2. These $\mathrm{H}_{2} \mathrm{O}$ measurements were needed for the corrections applied to some of the $\mathrm{CH}_{4}$ fluxes (Sect. 3). Due to precise pressure control, the G1301-f cell pressure remained constant throughout the campaign. Cell pressures of FMA1, FMA2 and LI-7000 varied slightly and QCL cell pressure was not recorded (Table 1). No significant difference in performance between the different pump types used was found.

\section{Data post-processing}

\subsection{Introduction}

Under the assumptions of turbulence stationarity, a horizontally homogeneous surface and turbulence characteristics, the mass balance equation is reduced into a simple form which is the basis of eddy covariance measurements:

$F_{c}=\frac{\overline{\rho_{\mathrm{d}}}}{M_{\mathrm{d}}} \overline{w^{\prime} r_{c}^{\prime}}$, where $F_{c}$ is the flux of gas $c$ at the surface, $\overline{\rho_{\mathrm{d}}}$ is mean dry air density, $M_{\mathrm{d}}$ is the molar mass of dry air, $w$ the vertical wind component and $r_{c}$ is the dry mole fraction of gas $c\left(r_{c}=\frac{N_{c}}{N_{\text {dry air }}}\right.$, where $N$ is the number of moles). Following Reynolds decomposition, overbars denote mean values and primes (') fluctuations around the mean. However, usually gas analysers do not report dry mole fraction $\left(r_{c}\right)$; rather they report wet mole fraction (i.e. total mole fraction, $\chi_{c}$ ), or in the case of open-path analysers the gas molar density, which is affected by fluctuations in temperature and humidity. In addition, the instruments used to measure gas concentrations and wind components are non-ideal, i.e. they do not make truly instantaneous measurements and therefore act as bandpass filters effectively filtering out certain high and low frequencies in the signal. Both of these effects need to be corrected for, in addition to other post-processing steps, before the measured flux represents the flux at the surface. The correction methods used in this study are discussed in greater detail in the following sections.

\subsection{General data post-processing steps}

Data obtained during the campaign were post-processed with the EddyUH software (freely available at: http://www.atm.helsinki.fi/Eddy_Covariance/index.php).

The post-processing was done according to the following steps:

- First the $\mathrm{CH}_{4}$ time series were converted with calibration parameters (Table 2) from measured ppm $\left(\mathrm{mmol} \mathrm{m}{ }^{-3}\right.$ for LI-7700) to calibrated units. The parameters were obtained with the method described in Sect. 3.3.

- The raw eddy covariance data were despiked by comparing two temporally adjacent $\mathrm{CH}_{4}$ concentration measurements. If their difference was larger than $3 \mathrm{ppm}$ the following point was considered a spike and was replaced with the value of the previous data point. For LI-7700 also data points were considered as spikes, for which the diagnostic value indicated by the instrument was 32768 (instrument not ready), 16384 (no laser signal detected) or 8192 (reference methane signal not locked).

- For closed-path instruments which also measured $\mathrm{H}_{2} \mathrm{O}$, the effects of fluctuating humidity on $\mathrm{CH}_{4}$ measurements were corrected point-by-point according to Eq. (4) below, with coefficients given in Table 3.

- The coordinate system of the sonic anemometer was rotated using the double rotation method (Rebmann et al., 2012), aligning the $x$ axis of the anemometer with the mean flow.

- Linear detrending was used to separate the turbulent signal from the measurements, and the covariances were 
Table 2. Calibration coefficients for different instruments used in this study. Values for offset are given in ppm for gas analysers other than LI-7700. For LI-7700 the coefficient is given in $\mathrm{mmol} \mathrm{m}^{-3}$. Values for the coefficient of determination are given in the last column. LI-7700 data are affected by an external data-logging problem (Sect. 2.2).

\begin{tabular}{llrrr}
\hline Gas analyser & Applied after & Offset & Gain & $R^{2}$ \\
\hline LI-7700 & $06 / 06 / 2012$ & 0.0047 & 0.901 & 0.67 \\
G2311-f & $06 / 06 / 2012$ & 0.014 & 0.983 & 0.96 \\
G1301-f & $06 / 06 / 2012$ & -0.036 & 1.030 & 0.97 \\
FGGA & $06 / 06 / 2012$ & 0.033 & 0.971 & 0.95 \\
FMA1 & $06 / 06 / 2012$ & -0.072 & 1.055 & 0.94 \\
FMA2 & $06 / 06 / 2012$ & 0.033 & 1.001 & 0.94 \\
& $20 / 06 / 2012$ & -0.143 & 1.074 & 0.96 \\
DLT-100 & $06 / 06 / 2012$ & -0.077 & 1.039 & 0.93 \\
& $18 / 06 / 2012$ & -0.225 & 1.099 & 0.96 \\
QCL & $06 / 06 / 2012$ & -0.155 & 1.092 & 0.83 \\
& $13 / 06 / 2012$ & -0.252 & 1.227 & 0.80 \\
& $21 / 06 / 2012$ & 0.114 & 0.953 & 0.85 \\
\hline
\end{tabular}

calculated by searching the maximum of the crosscovariance function within certain predefined lag windows. A 30 min averaging period was used for all fluxes.

- Within an iterative loop, the resulting $\mathrm{CH}_{4}$ fluxes were corrected for the effect of fluctuating humidity and also for fluctuating temperature for the open-path LI-7700 instrument (Sect. 3.4). Temperature fluctuations are expected to be fully damped in the closed-path systems used.

- Finally, the fluxes were corrected for high- and lowfrequency damping, based on the method described by Aubinet et al. (2000).

The overall correction factor CF used to correct for band-pass filtering was calculated as

$$
\mathrm{CF}=\frac{\int_{0}^{\infty} C_{\bmod }(f) \mathrm{d} f}{\int_{0}^{\infty} \operatorname{TF}_{\mathrm{LF}}(f) \operatorname{TF}_{\mathrm{HF}}(f) C_{\bmod }(f) \mathrm{d} f},
$$

where $\mathrm{TF}_{\mathrm{LF}}$ is a transfer function describing low-frequency dampening, adopted from Rannik and Vesala (1999), $\mathrm{TF}_{\mathrm{HF}}$ is a transfer function which describes high-frequency damping, $C_{\text {mod }}$ is a scalar model cospectrum and $f$ is natural frequency. $C_{\text {mod }}$ was determined by fitting a curve to ensemble averaged temperature cospectra. $\mathrm{TF}_{\mathrm{HF}}$ was determined experimentally by fitting the Lorentzian function (Eq. 3), which is based on a first-order recursive filter (Eugster and Senn, 1995), to the ratio between measured $\mathrm{CH}_{4}$ and temperature cospectra.

$\mathrm{TF}_{\mathrm{HF}}=\frac{1}{1+(2 \pi f \tau)^{2}}$ $\tau$ is a measurement system-specific fit parameter which characterises the high-frequency filtering effects.

\subsection{Calibration coefficients}

The analysers had not been calibrated against common standards prior to the start of the inter-comparison exercise. In order to minimise the differences in the $\mathrm{CH}_{4}$ fluxes caused by different calibrations, the following procedure was applied: 30 min mean values for the mole fractions were calculated for each $\mathrm{CH}_{4}$ mole fraction time series. These values were compared with high-accuracy measurements (calibrated against the NOAA2004 concentration scale) made at $20 \mathrm{~m}$ height at the CESAR tower with another G2301 instrument (Picarro Inc., USA). Only daytime periods (between 09:00 and 21:00), when the $\mathrm{CH}_{4}$ concentration difference between 20 and $60 \mathrm{~m}$ heights was smaller than $15 \mathrm{ppb}$, were used. Under such circumstances, the concentrations measured at $20 \mathrm{~m}$ and $6.5 \mathrm{~m}$ heights were assumed to be sufficiently similar. A simple linear regression between $20 \mathrm{~m}$ height measurements and $\mathrm{CH}_{4}$ mole fraction time series derived from EC measurements was used to obtain the calibration parameters (offset and gain) (Table 2) for each $\mathrm{EC} \mathrm{CH}_{4}$ time series. For the QCL three sets of coefficients were determined since the fitting procedure of the instrument was changed two times during the campaign and this had an effect on the reported $\mathrm{CH}_{4}$ values. For the FMA2 and DLT-100 two sets of coefficients were determined: for FMA2 the calibration changed since the sampling cell was cleaned and for the DLT-100 it changed due to restarting the instrument, which caused a sudden decrease in the cavity ringdown time and consequently a slight change in calibration.

\subsection{Corrections for density and spectroscopic effects}

Humidity and temperature fluctuations affect gas flux measurements by causing changes in air density (Webb et al., 1980; Massman and Tuovinen 2006; Ibrom et al., 2007b) and, for gas analysers based on laser absorption spectrometry, also by altering the shape of the gas absorption line (McDermitt et al., 2010; Neftel et al., 2010; Tuzson et al., 2010). Corrections for these effects are referred to as density and spectroscopic correction, respectively.

Rella (2010) proposed to correct both of these effects for closed-path gas analysers by using a second-order polynomial function

$\chi_{c}=r_{c}\left(1+a \chi_{v}+b \chi_{v}^{2}\right)$,

where $\chi_{c}$ is the wet mole fraction of gas $c, r_{c}$ is the dry mole fraction of gas $c$ corrected for any interference from water, $\chi_{v}$ is the $\mathrm{H}_{2} \mathrm{O}$ mole fraction and $a$ and $b$ are instrumentspecific coefficients which describe the dependence of $\chi_{c}$ on $\chi_{v}$. This expression has been demonstrated to be suitable for correcting measurements for dilution (i.e. density correction for closed-path gas analysers) and spectroscopic effects in 
Table 3. Spectroscopic coefficients used in Eqs. (4) or (5) for different gas analysers.

\begin{tabular}{lccl}
\hline Gas analyser & $\begin{array}{c}a \\
\left(\left(\mathrm{~mol} \mathrm{~mol}^{-1}\right)^{-1}\right)\end{array}$ & $\begin{array}{c}b \\
\left(\left(\mathrm{~mol} \mathrm{~mol}^{-1}\right)^{-2}\right)\end{array}$ \\
\hline G1301-f (Picarro) & -1.27 & 0.14522 & Rella (2010) \\
FGGA (Los Gatos Res.) & -1.189 & 0.2096 & Hiller et al. (2012) \\
FMA (Los Gatos Res.) & -1.219 & 1.678 & Hiller et al. (2012) \\
DLT-100 (Los Gatos Res.) & -1.219 & 1.678 & Hiller et al. (2012) \\
\hline
\end{tabular}

several studies (Chen et al., 2010; Hiller et al., 2012; Nara et al., 2012; Rella et al. 2013), and it is nowadays widely used. It is worth noting that Eq. (4) is reduced to the correction for dilution alone for $a=-1$ and $b=0$. This form of correction is easily applicable if the closed-path gas analyser measures both, $\chi_{c}$ and $\chi_{v}$, and in fact is implemented into some of the instruments that can thus report a dry mole fraction (e.g. G2311-f, which uses coefficients from Chen et al., 2010). However, some of the laser spectrometers used in this study did not measure $\mathrm{H}_{2} \mathrm{O}$ and thus external $\mathrm{H}_{2} \mathrm{O}$ measurements were needed. When using external $\mathrm{H}_{2} \mathrm{O}$ measurements, it may be preferable to apply the corrections to the half-hourly averaged fluxes, instead of correcting the raw data point-by-point, since this way the possible discrepancies between the external and internal $\chi_{v}$ are not passed on to the high-frequency $\chi_{c}$ time series. By using Reynolds decomposition, averaging and slightly reorganising the terms, the expression above can be converted into flux form (see Appendix A for derivation):

$$
\begin{aligned}
F_{c} & =\frac{\overline{\rho_{a}}}{\overline{M_{a}}} \frac{1-\overline{\chi_{v}}}{1+a \overline{\chi_{v}}+b{\overline{\chi_{v}}}^{2}}\left(\overline{w^{\prime} \chi_{c}^{\prime}}+\frac{\overline{\chi_{c}}}{1-\overline{\chi_{v}}} \overline{w^{\prime} \chi_{v}^{\prime}}\right. \\
& \left.-\frac{a+2 b \overline{\chi_{v}}-b{\overline{\chi_{v}}}^{2}+1}{\left(1+a \overline{\chi_{v}}+b{\overline{\chi_{v}}}^{2}\right)\left(1-\overline{\chi_{v}}\right)} \overline{\chi_{c}} \overline{w^{\prime} \chi_{v}^{\prime}}\right) \\
& =\frac{1-\overline{\chi_{v}}}{1+a{\overline{\chi_{v}}}^{2} b{\overline{\chi_{v}}}^{2}}\left(F_{c}^{\mathrm{RAW}}+F_{c}^{\mathrm{WPL}}+F_{c}^{\mathrm{SPECT}}\right)
\end{aligned}
$$

where $\overline{\rho_{a}}$ is the mean total air density and $\overline{M_{a}}$ is the mean molar mass of moist air. The first term on the right-hand side is the measured flux ( $\left.F_{c}^{\mathrm{RAW}}\right)$, the second term is the effect of air density fluctuations ( $F_{c}^{\mathrm{WPL}}, \mathrm{H}_{2} \mathrm{O}$ term in WPL correction) and the third term $\left(F_{c}^{\mathrm{SPECT}}\right)$ and the multiplier in front of the parentheses arise from the spectroscopic effects that $\mathrm{H}_{2} \mathrm{O}$ has on the measurements of gas $c$.

One should note that Eq. (5) is identical to Eq. (3a) in Ibrom et al. (2007b) if we take $a=-1$ and $b=0$, meaning that the spectroscopic effects are neglected, and only the effect of density fluctuations is corrected. In addition, it should be emphasised that under normal circumstances the two correction methods presented above (Eqs. 4 and 5) will deliver the same result, if and only if the covariance $\overline{w^{\prime} \chi_{v}^{\prime}}$ reflects the variation in $\mathrm{H}_{2} \mathrm{O}$ mole fraction in the measurement cell when gas $c$ is measured, a point which has been highlighted for density correction (Ibrom et al., 2007b; Massman, 2004).
This also applies to spectroscopic correction and to the combined correction presented in Eq. (5).

The coefficients $a$ and $b$ used for the different gas analysers are listed in Table 3. For FMA2 and FGGA the correction was done point-by-point applying Eq. (4) with the $\mathrm{H}_{2} \mathrm{O}$ concentration measured within the instrument; for some of the instruments with no in situ measurement of $\mathrm{H}_{2} \mathrm{O}$ (i.e. G1301-f and DLT-100), the correction was performed using Eq. (5), and the covariance $\overline{w^{\prime} \chi_{v}^{\prime}}$ was adjusted using the empirical procedure described below (Sect. 3.4.1). For FMA1 it was performed using Eq. (5) and the $\mathrm{H}_{2} \mathrm{O}$ covariance from the LI-7000, $\overline{w^{\prime} \chi_{v}^{\prime}}$, calculated with FMA1 $\mathrm{CH}_{4}$ lag time because LI-7000 and FMA1 shared the same inlet line. $\mathrm{CH}_{4}$ signals from the G2311-f and the QCL were free from $\mathrm{H}_{2} \mathrm{O}$ interference since the G2311-f applied a similar correction internally during the measurements and the QCL was connected to a drier, and it is assumed that the drier completely removes the effect of $\mathrm{H}_{2} \mathrm{O}$ on the sampled $\mathrm{CH}_{4}$. Open-path gas analyser LI-7700 $\mathrm{CH}_{4}$ measurements are not only affected by the $\mathrm{H}_{2} \mathrm{O}$, but also by temperature fluctuations, and the resulting $\mathrm{CH}_{4}$ fluxes were corrected with the method proposed by McDermitt et al. (2010).

\subsubsection{Using external $\mathrm{H}_{2} \mathrm{O}$ in correcting $\mathrm{CH}_{4}$ fluxes}

Adsorption/desorption of $\mathrm{H}_{2} \mathrm{O}$ molecules on the sampling tube walls and filters (closed-path gas analysers only) cause amplitude and phase shifts compared to an unperturbed, ideal signal (Fratini et al., 2012; Ibrom et al., 2007a; Mammarella et al., 2009; Massman and Ibrom, 2008; Nordbo et al., 2013; Runkle et al., 2012). Thus, $\mathrm{H}_{2} \mathrm{O}$ lag times tend to be longer than for other gases in the same sampling tube and attenuations of $\mathrm{H}_{2} \mathrm{O}$ fluctuations are enhanced. Adsorption/desorption of $\mathrm{H}_{2} \mathrm{O}$ depends on sampling line characteristics, i.e. tube material, flow rate, filter, etc. Moreover, the mechanisms are enhanced when relative humidity increases and/or dirt accumulates on the wall of the tube. This enhancement is sampling line-specific (Ibrom et al., 2007a; Mammarella et al., 2009). To date a comprehensive explanation for the amplitude and phase shifts is missing. However, Nordbo et al. (2013) showed promising development in this respect.

A problem arises from the fact that the attenuation and phase shift of $\mathrm{H}_{2} \mathrm{O}$ are not known in the sampling lines of those gas analysers not capable of measuring $\mathrm{H}_{2} \mathrm{O}$. Thus, 
correcting $\mathrm{CH}_{4}$ data for the $\mathrm{H}_{2} \mathrm{O}$ effect is difficult. To partly overcome these difficulties, the following procedure was used to estimate the phase shift between $\mathrm{H}_{2} \mathrm{O}$ and other scalars. First, the ratio of $\mathrm{H}_{2} \mathrm{O}$ and $\mathrm{CO}_{2}$ lag times in the LI7000 sampling line was parameterised as a function of RH:

$$
\frac{t_{\mathrm{H}_{2} \mathrm{O}}}{t_{\mathrm{CO}_{2}}}=c+d\left(\frac{\mathrm{RH}}{100}\right)^{e},
$$

where RH is the relative humidity in \%. Data were grouped into 12 relative humidity classes and the fit parameters $c, d$ and $e$ were obtained by fitting the above expression to median values in 12 relative humidity classes $\left(r^{2}=0.9963\right.$ and RMSE $=0.0841)$, yielding the values $c=1.081$ (95\% confidence bounds: 1.002-1.159), $d=6.369$ (5.849-6.888) and $e=14.06$ (12.43-15.69). It was then assumed that the ratio has the same relative humidity dependence in all sampling lines and, finally, the $\mathrm{H}_{2} \mathrm{O}$ covariance, $\overline{w^{\prime} \chi_{v}^{\prime}}$, used in Eq. (5) was calculated with a lag time of

$t=t_{\mathrm{H}_{2} \mathrm{O}}^{\mathrm{ANA} 2}-\left(\left(c+d\left(\frac{\mathrm{RH}}{100}\right)^{e}\right) t_{\mathrm{CH}_{4}}^{\mathrm{ANA} 1}-t_{\mathrm{CH}_{4}}^{\mathrm{ANA} 1}\right)$

$t=t_{\mathrm{H}_{2} \mathrm{O}}^{\mathrm{ANA} 2}-\Delta t$,

where $t_{\mathrm{H}_{2} \mathrm{O}}^{\mathrm{ANA} 2}$ is the lag time of $\mathrm{H}_{2} \mathrm{O}$ measured with for instance LI-7000, and $t_{\mathrm{CH}_{4}}^{\mathrm{ANA} 1}$ is the lag time of $\mathrm{CH}_{4}$ measured with for instance FMA. $\Delta t$ takes into account the phase shift between $\mathrm{H}_{2} \mathrm{O}$ and $\mathrm{CH}_{4}$ in the sampling line. Now, instead of calculating $\overline{w^{\prime} \chi_{v}^{\prime}}$ with $t_{\mathrm{H}_{2} \mathrm{O}}^{\mathrm{ANA}}$, which corresponds to maximising the covariance, the covariance is calculated with $t$ and then Eq. (5) was applied. No attempt was made to correct for differences in attenuation of $\mathrm{H}_{2} \mathrm{O}$ in different sampling lines. Moreover, the assumption that the ratio between $\mathrm{H}_{2} \mathrm{O}$ and $\mathrm{CO}_{2}$ lag times follows the same relative humidity dependence in all sampling lines may not necessarily be valid.

\subsection{Random errors in the flux}

When evaluating instrument performance, it is vital to know how much noise there is in the measured signal. In many situations the random error of an eddy covariance flux measurement is dominated by one-point sampling uncertainty (Businger, 1986; Kroon et al., 2010), caused by the stochastic nature of turbulence, rather than by instrumental noise. In this study, the total random uncertainty of a flux estimate is calculated with the method proposed by Finkelstein and Sims (2001). In this method, the error variance of the covariance is estimated based on cross-covariances and auto-covariances and thus the uncertainty estimate contains contributions originating from sampling uncertainty and instrumental noise.

Lenschow et al. (2000) introduced a method to estimate instrumental noise of LiDAR measurements, and later Mauder et al. (2013) applied it to eddy covariance data. Due to the fact that instrumental noise is uncorrelated with the turbulent signal, it can be assumed that the noise contributes to the auto-covariance only at lag zero. Thus, the instrumental noise can be estimated as the difference between the observed value of auto-covariance at lag zero (i.e. variance of the time series) and extrapolation of auto-covariance function values to lag zero:

$\left(\sigma_{c}^{\text {noise }}\right)^{2}=C_{11}(0)-C_{11}(p \rightarrow 0)$,

where $C_{11}=C_{11}(p)$ is the auto-covariance function, $p$ is the lag and $C_{11}(p \rightarrow 0)$ is the extrapolation of auto-covariance function to lag zero. $C_{11}(p \rightarrow 0)$ was estimated using linear extrapolation and auto-covariance values at lags $4 \leq p \leq 11$ were used for the extrapolation. In essence, with this method the observed variance of time series $C_{11}(0)$ is divided into two parts: variance caused by turbulent mixing, $C_{11}(p \rightarrow 0)$, and variance caused by instrumental noise $\left(\sigma_{c}^{\text {noise }}\right)^{2}$. Therefore, $\sigma_{c}^{\text {noise }}$ describes the noise level in the measured time series. Contribution of this noise to uncertainty in the covariance is estimated using error propagation (Eq. 7 in Mauder et al., 2013):

$\sigma_{w, c}^{\text {noise }}=\sqrt{\frac{\left(\sigma_{c}^{\text {noise }}\right)^{2} \sigma_{w}^{2}}{N}}$

where $N$ is the number of samples in a time series and $\sigma_{w}^{2}$ is the variance of the vertical wind component. Unlike in the original equation given in Mauder et al. (2013), the contribution of instrumental noise in $w$ was neglected since the focus was on comparing the gas analysers. This method is sensitive only to random noise, i.e. white noise, in the signal and it cannot be used to estimate drift or low-frequency noise in the signal, since such variations contribute to auto-covariance at multiple lag times, not just at lag zero.

Eddy covariance fluxes are usually estimated by maximising the cross-covariance between time series $w$ and $\chi_{c}$. Wienhold et al. (1995) developed a method to assess how well this maximum can be detected from the cross-covariance. In their method the detection limit of a flux is estimated as the standard deviation of the cross-covariance function values far from the maximum value, i.e. the flux. In essence, this method estimates the magnitude of the background variation of the cross-covariance. In this study the detection limits were estimated by using the position of the maximum as the origin of time, calculating the cross-covariance between time series $w$ and $\chi_{c}$ within lag windows $-150 \mathrm{~s}$ to $-50 \mathrm{~s}$ and $50 \mathrm{~s}$ to $150 \mathrm{~s}$, and finally calculating the standard deviation of the obtained cross-covariance values.

\subsection{Flux data filtering and quality control}

The flux data were screened in order to remove clearly erroneous values. Flux data were removed if there were too many spikes during an averaging period (over 3000 spikes), $30 \mathrm{~min}$ mean $\mathrm{CH}_{4}$ mole fractions were unrealistic (below $1.7 \mathrm{ppm}$ or above $3.5 \mathrm{ppm}$ ) or sonic anemometer data were erroneous. 
In addition, the open-path LI-7700 data were screened based on the RSSI (received signal strength indicator) and the diagnostic value provided by the instrument. The diagnostic value describes instrument activities during operation and RSSI represents how clean the mirrors in the open measurement cell are. Periods were omitted if the 30 min mean value for RSSI was below 15. Periods were also rejected if no laser signal was detected for more than $5 \%$ of the time, or if over $3 \%$ of the time the lower mirror spin motor was on. In addition to these criteria, a few clear outliers were removed from the LI-7700 data based on visual inspection. A threshold of $0.08 \mathrm{~m} \mathrm{~s}^{-1}$ for friction velocity $\left(u_{*}\right)$ was determined based on the measured data and was used to discard periods with low turbulent mixing. This threshold was used for all $\mathrm{CH}_{4}$ fluxes. The fluxes were distributed into three quality classes based on a flux stationarity test (Foken and Wichura, 1996). If the test yielded values smaller than 0.3 , the fluxes were given quality flag 0 (highest quality), fluxes with test values between 0.3 and 1 were given flag 1 (medium quality) and if the test yielded values above 1 , then the fluxes were flagged with 2 (low quality).

\section{Results}

\subsection{Data coverage and quality}

The poorest data coverage (Fig. 2) was obtained with the G1301-f and DLT-100 instruments (26.7 and 64.4\%, respectively); however, this was caused by data-logging problems and does not reflect instrument performance. FGGA and G2311-f achieved the best data coverage, which also often had the high-quality flag (Fig. 3).

The largest data filtering effect using the screening procedure described in Sect. 3.6 was for the LI-7700, with approximately $43 \%$ of data rejected. This was mainly related to one period (from 9 June to 14 June 2012) during which both mirrors became dirty and manual cleaning was not possible. From 18 June onwards the mirrors were cleaned manually every second day. The friction velocity criterion removed 66 30 min $\mathrm{CH}_{4}$ flux data points (6\% of data) from all time series.

\subsection{Random errors and instrumental noise}

The statistics of the estimates for instrumental noise levels are shown for each instrument in Fig. 4 for periods when all gas analysers were working. The noise was not estimated for the LI-7700 due to the data-logging problem (explained in Sect. 2.2). On average, the two Picarro analysers, G2311$\mathrm{f}$ and G1301-f, had the lowest instrumental noise ( 0.4 and $1.2 \mathrm{ppb}$, respectively) during the study period (Fig. 4a and b). It is however questionable whether the method used can adequately separate the turbulent signal from the instrumental noise in the case of the G2311-f for which the overall noise level was very small. For comparison, the standard deviations

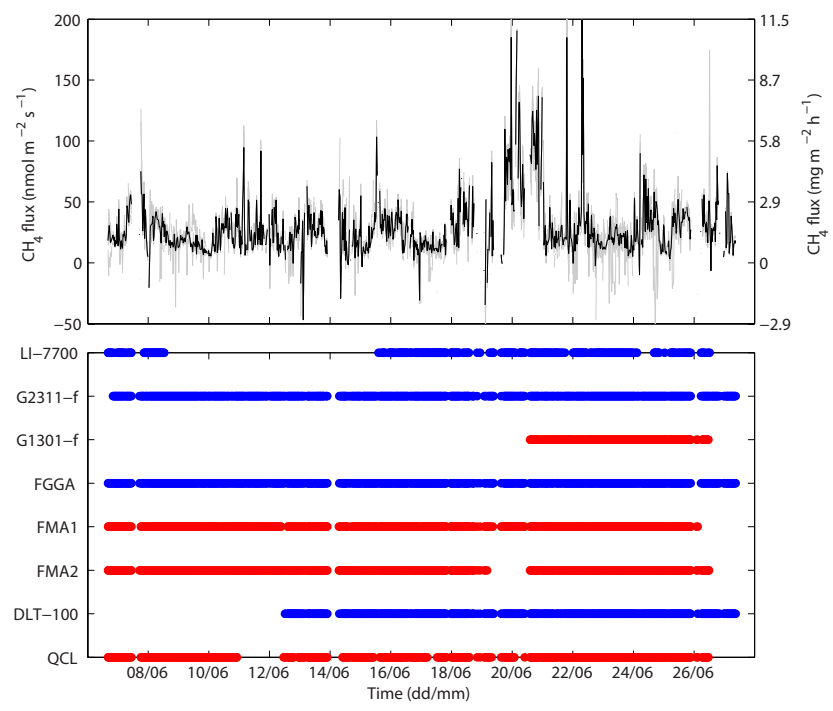

Figure 2. Upper plot shows $\mathrm{CH}_{4}$ flux time series (grey lines: individual $\mathrm{CH}_{4}$ flux time series; black line: median $\mathrm{CH}_{4}$ flux time series) and the bottom plot shows periods when gas analysers were working. Red colour corresponds to fluxes measured with METEK2 and blue to fluxes measured with METEK1.

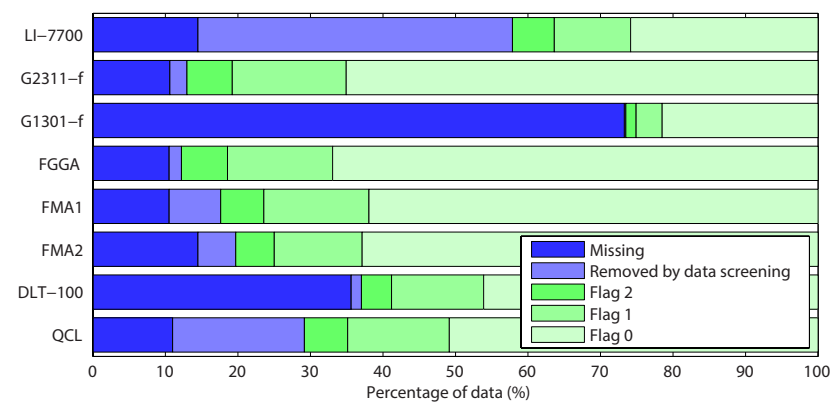

Figure 3. Distribution of quality flags for $\mathrm{CH}_{4}$ fluxes during the campaign. Quality flags were given according to flux stationarity criteria (Foken and Wichura, 1996). Flag 0 (flux stationarity below 0.3 ) corresponds to the highest quality, flag 1 (flux stationarity between 0.3 and 1) to medium quality and flag 2 to the lowest quality (flux stationarity above 1). Green bars show the amount of accepted data and blue bars shown the amount of omitted data. LI7700 data are affected by an external data-logging problem which is not caused by the analyser.

of $\mathrm{CH}_{4}$ mole fractions, which contain contributions from both instrumental noise and atmospheric fluctuations, measured by the two Picarro instruments were approximately 4.6 and $4.3 \mathrm{ppb}$, respectively. Thus the variations in the $\mathrm{CH}_{4}$ time series from these two analysers were clearly dominated by atmospheric fluctuations rather than instrumental noise. This is evident in the example fast-response time series shown in Fig. 5. For the two Picarro instruments the turbulent signal can easily be seen in the time series (high concentration during upward motion and close to ambient concentration during downward motion), while for the other instruments the 

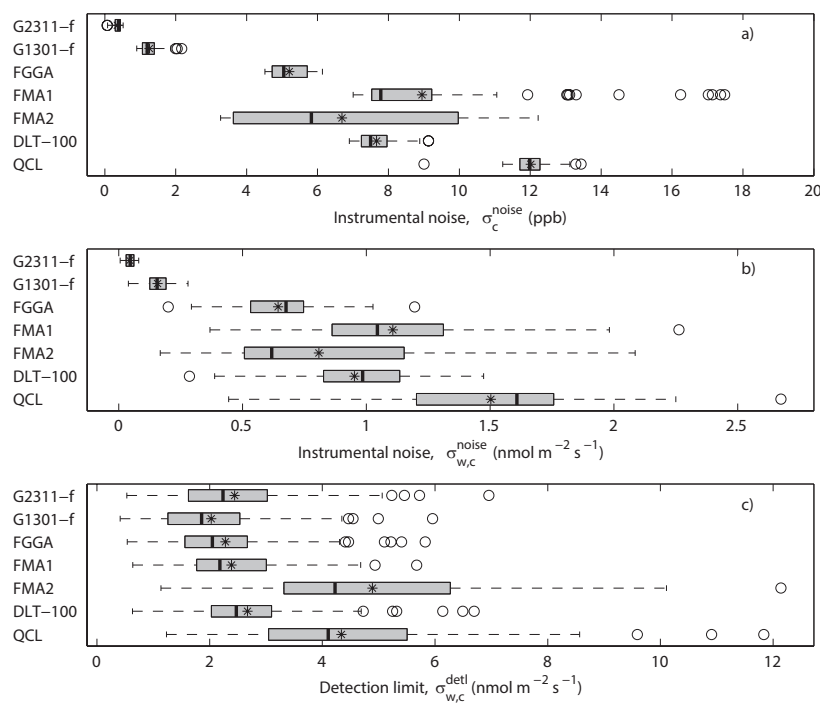

Figure 4. Boxplots of instrumental noise (upper two plots) and detection limit (bottom plot) calculated based on the methods presented in Sect. 3.5. Only periods when all the instruments were working and the $\mathrm{CH}_{4}$ flux was below $30 \mathrm{nmol} \mathrm{m}^{-2} \mathrm{~s}^{-1}$ were used (129 points) for the detection limit plot. For the instrumental noise plots periods when all the instruments were working and the instrumental noise was estimated successfully were used (99 points). Grey boxes show the interquartile range, vertical lines within the boxes show medians, stars show the means, dashed whiskers show the limits for outliers and circles show values outside these limits. LI-7700 is not shown due to the data-logging problem outside the instrument.

signal in $\mathrm{CH}_{4}$ concentration is mixed with instrumental noise and is therefore not visible as clearly. All the other gas analysers show much higher instrumental noise levels; FGGA had the smallest instrumental noise of the non-Picarro analysers, while QCL had the highest.

The low noise estimate for G2311-f data may be partly caused by the instrument's low measurement frequency $(2.3 \mathrm{~Hz}$; see Sect. 4.3.1 for an explanation), because noise decreases when increasing the sample size. Noise in $10 \mathrm{~Hz}$ G2311-f data can be roughly estimated by multiplying the noise estimate for $2.3 \mathrm{~Hz}$ data $(0.4 \mathrm{ppb})$ by $\sqrt{10 \mathrm{~Hz} / 2.3 \mathrm{~Hz}}$. This calculation yields a value of $0.8 \mathrm{ppb}$, which is closer to the value estimated for G1301-f, but still a lot smaller than what was approximated for other instruments.

The instrumental noise of the FMA1 was highly variable during the experiment and affected by cell temperature: when the cell temperature of the FMA1 was between $27^{\circ} \mathrm{C}$ and $29^{\circ} \mathrm{C}$, the instrumental noise was approximately $13.8 \mathrm{ppb}$ and reached up to $20 \mathrm{ppb}$, whereas in other situations (cell temperature above $29^{\circ} \mathrm{C}$ or below $27^{\circ} \mathrm{C}$ ) it was on average $6.8 \mathrm{ppb}$. The reason for this odd temperature dependence is unknown. The noise in the FMA2 data also responded to cell temperature, but not as strongly as for the FMA1 instru- ment. Instrumental noise from other analysers at Los Gatos Research did not show such strong temperature dependence.

The LGR analysers also report cavity ringdown (CRD) times which describe how long it takes for the laser signal to attenuate in the optical cavity. Roughly speaking the CRD time can be thought to represent cleanliness of the mirrors in the cavity: a short CRD time corresponds to dirty mirrors and a long CRD time to clean mirrors. For most of the LGR analysers the CRD times decreased significantly during the campaign due to dirt accumulating on the mirrors in the cavity. Only the FGGA had a rather stable CRD time throughout the campaign, around $11.7 \mu \mathrm{s}$, while for other LGR analysers the values at the end of the campaign were $7 \mu \mathrm{s}$. However, the instrumental noise did not significantly depend on the CRD time, and periods when it was around $7 \mu$ s were still usable for flux calculations. For example, for FMA1 the instrumental noise increased from 6.5 to $7.8 \mathrm{ppb}$ when the CRD time was above $10 \mu$ s or below $8 \mu$ s (only periods when cell temperature was above $29^{\circ} \mathrm{C}$ or below $27^{\circ} \mathrm{C}$ were considered).

The detection limits, shown in Fig. 4c, were approximately $2 \mathrm{nmol} \mathrm{m}^{-2} \mathrm{~s}^{-1}$, except for the QCL and the FMA2, which had higher values $\left(4 \mathrm{nmol} \mathrm{m}^{-2} \mathrm{~s}^{-1}\right)$. The flux detection limit estimated with this method is mostly determined by the stochastic nature of turbulence during the $30 \mathrm{~min}$ periods selected. For the QCL the high noise level also increased the value of the detection limit, but the higher detection limit for FMA2 is not explicable in terms of white noise, since for instance FMA1 had more white noise but a lower detection limit when compared to FMA2. The FMA2 signal was possibly also contaminated with (structured) noise rather than just white noise, which contributed more to the detection limit than to the instrumental noise. However, before the instrument was taken back to the laboratory for cleaning (19 June), the instrumental noise values were similar to those reported by other instruments (approximately $2 \mathrm{nmol} \mathrm{m}^{-2} \mathrm{~s}^{-1}$ ), which suggests that cleaning of the cavity was unsuccessful.

\subsection{Flux corrections}

\subsubsection{Spectral corrections}

Ensemble-averaged $\mathrm{CH}_{4}$ cospectra are shown in Figs. 6 and 7 , together with the corresponding temperature cospectra. In the ideal case the $\mathrm{CH}_{4}$ cospectra would collapse onto the temperature cospectra and both would follow the model cospectrum, which is also shown for reference. However, all $\mathrm{CH}_{4}$ cospectra fell below the temperature cospectrum at the high-frequency end.

As the flux is the integral of the cospectrum, it is clear that the contribution of the high-frequency fluctuations (small eddies) is underestimated and should be corrected. This is done with the method presented in Sect. 3.2; the response times used for the corrections are given in the figures. G2311-f had the slowest response time, which was caused by instrument malfunction: although the instrument was set to measure at 

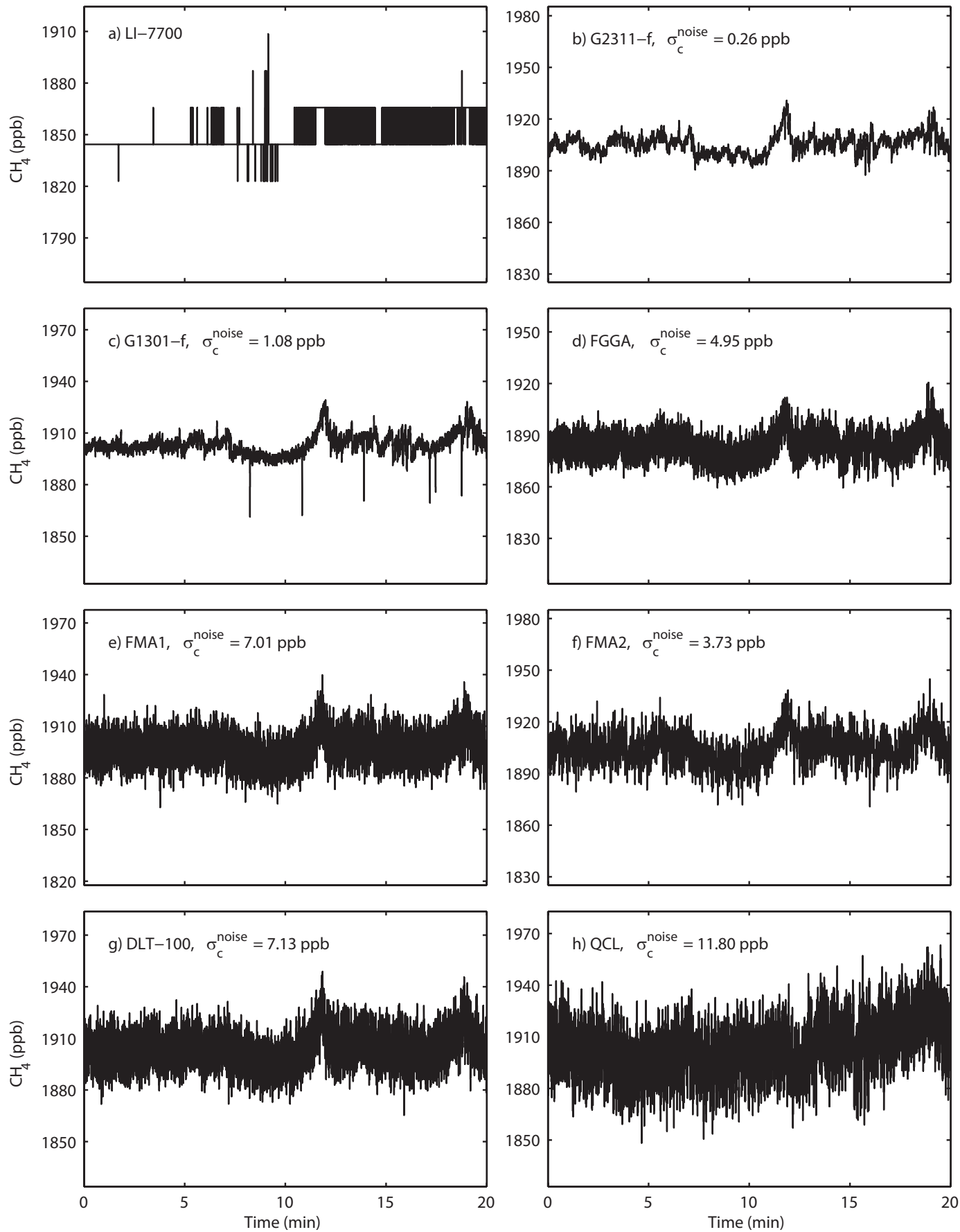

Figure 5. Example of raw $\mathrm{CH}_{4}$ concentration data from each instrument. Data were measured on 22 June 2012, between 10:40 and 11:00. Corresponding instrumental noise estimates are also shown in the figure, except for LI-7700. The LI-7700 data are clearly affected by the external data-logging problem which is not caused by the analyser.

$10 \mathrm{~Hz}$, it was effectively measuring at approximately $2.3 \mathrm{~Hz}$, and the recorded $10 \mathrm{~Hz}$ data were a linear interpolation of the $2.3 \mathrm{~Hz}$ data. Thus frequencies exceeding $2.3 \mathrm{~Hz}$ were lost. The reason for this malfunction is unknown, but it could have been caused by a memory leak produced by some additional code designed specifically for this campaign and added to the instrument's internal software (Gloria Jacobson, Picarro Inc., personal communication). Thus, if this is the case, other G2311-f analysers should not be affected.

The magnitudes of spectral corrections are presented in Fig. 8 as percentages of the measured raw fluxes. At close to $40 \%$, the correction was largest for the G2311-f. This is 

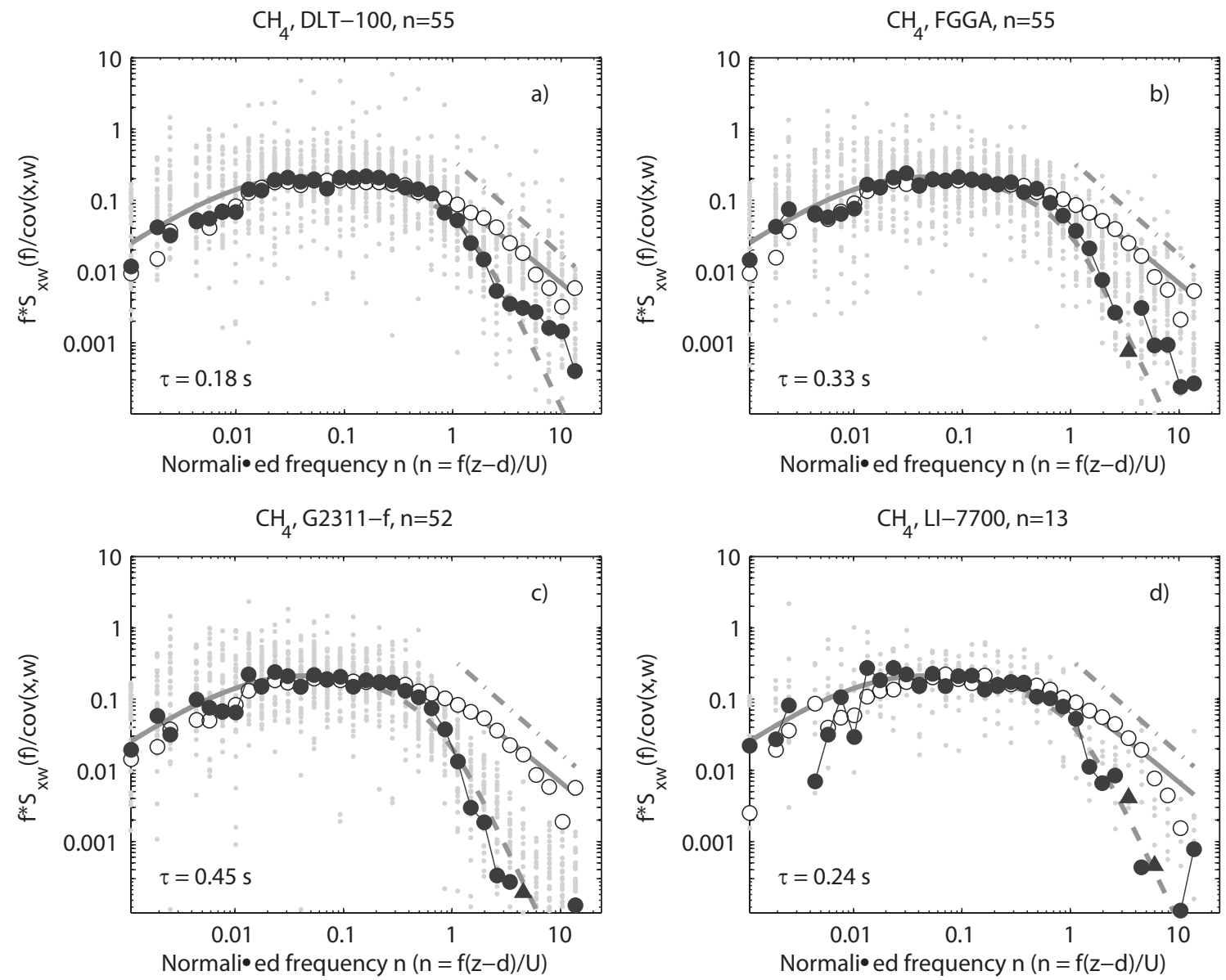

Figure 6. Normalised frequency-weighted $\mathrm{CH}_{4}$ cospectra between $\mathrm{CH}_{4}$ and vertical wind velocity for the different instruments associated with the METEK1 anemometer (black dots show positive values, black triangles negative values), corresponding temperature cospectra (white dots), theoretical slope $-4 / 3$ in the inertial subrange (dash-dotted line), model cospectrum (grey line) and model cospectrum multiplied by transfer function describing high-frequency attenuation, Eq. (3) (dashed grey line). Response time describing high-frequency attenuation is given in the figure for each gas analyser. Small grey dots show individual cospectra from which the mean cospectrum (black markers) is calculated. For this figure data were selected from the period 19 to 27 June, using only unstable periods when (a) $\mathrm{CH}_{4}$ flux was directed upwards, (b) wind speed was between $2 \mathrm{~m} \mathrm{~s}^{-1}$ and $6 \mathrm{~m} \mathrm{~s}^{-1}$, (c) $\mathrm{CH}_{4}$ fluxes were flagged with quality flag 0 and (d) more than $60 \%$ of the points in the normalised cospectra were positive. The LI-7700 data are affected by an external data-logging problem which is not caused by the analyser.

not surprising since it had the slowest response time. For the other $\mathrm{CH}_{4}$ fluxes the correction ranged from 10 to $30 \%$ of the originally measured flux.

\subsubsection{Density and spectroscopic corrections}

As a test, the $\mathrm{CH}_{4}$ fluxes of the FGGA were calculated by applying the $\mathrm{H}_{2} \mathrm{O}$ corrections point-by-point (Eq. 4) and comparing these values to half-hourly fluxes calculated using block-averaging and corrected using Eq. (5). The linear fit to the data processed with the two methods has a slope of 1.000 and an intercept of $-0.001 \mathrm{nmol} \mathrm{m}^{-2} \mathrm{~s}^{-1}$, and the RMSE and correlation coefficient $(r)$ are $0.008 \mathrm{nmol} \mathrm{m}^{-2} \mathrm{~s}^{-1}$ and 1.000 , respectively. The excellent agreement between the data sets confirms that the two correction methods are nearly identical and that the choice of correction method should not induce a systematic bias between the instruments, as long as the $\mathrm{H}_{2} \mathrm{O}$ flux used in Eq. (5) is calculated with the same lag time as the $\mathrm{CH}_{4}$ flux.

The magnitudes of density and spectroscopic corrections are given in Fig. 8. The density correction was on average approximately $10 \%$ during the day and a few percent at night when $\mathrm{H}_{2} \mathrm{O}$ fluxes were small. Spectroscopic corrections were much smaller: a few percent during the day and less than a percent at nighttime. However, the LI-7700 is an exception: the density correction was on average $40 \%$ during the day and $-27 \%$ at night. In addition, the spectroscopic correction was also larger (daytime $14 \%$, nighttime $-13 \%$ ). The difference between the LI-7700 and the other gas analysers is caused by the fact that the effect of temperature must be taken 

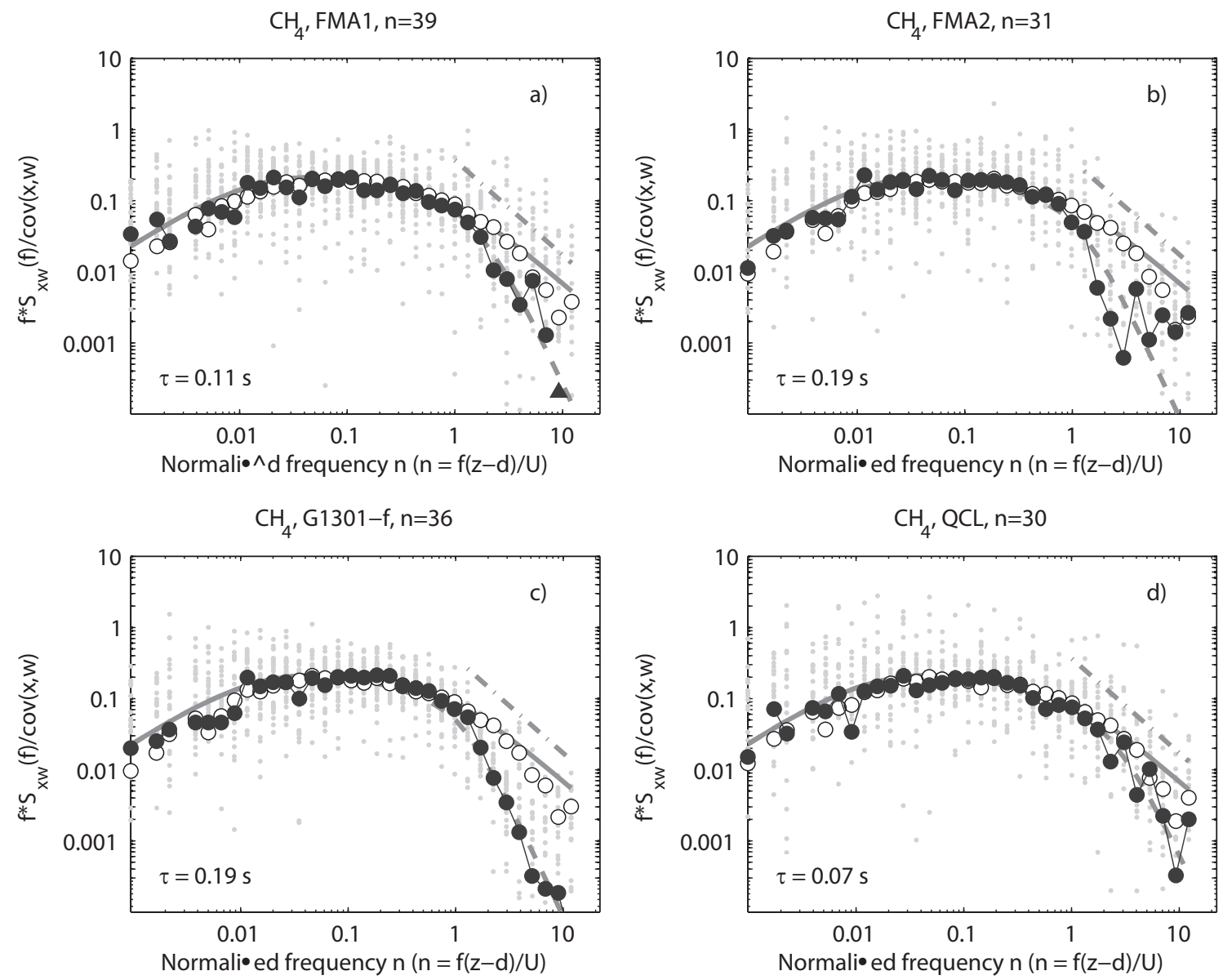

Figure 7. $\mathrm{CH}_{4}$ cospectra obtained with METEK2. For plot details refer to Fig. 6 .

into account in the case of the open-path analyser, while temperature fluctuations are smoothed out for closed-path sensors with long inlet lines.

To validate the density and spectroscopic corrections applied, the corrected $\mathrm{CH}_{4}$ fluxes were compared with the fully corrected $\mathrm{G} 2311-\mathrm{f} \mathrm{CH}_{4}$ flux. This instrument does both corrections automatically during measurement using coefficients reported in Chen et al. (2010) and it has been shown that the automatic correction implemented in Picarro instruments performs well (e.g. Rella et al., 2013). Thus the fully corrected $\mathrm{G} 2311-\mathrm{f} \mathrm{CH}_{4}$ flux is a good reference for the other instruments and there should not be any residual $\mathrm{H}_{2} \mathrm{O}$ effect left in G2311-f fluxes. A linear correlation between the difference in $\mathrm{CH}_{4}$ flux and the density correction term $\left(F_{\mathrm{CH}_{4}}^{\mathrm{WPL}}\right.$, the second term on the right-hand side in Eq. 5) was used to evaluate if the corrections were done properly (Fig. 9 shows an example using FGGA data). If the slope equals zero, the $\mathrm{H}_{2} \mathrm{O}$ corrections were done correctly and the differences between the $\mathrm{CH}_{4}$ flux time series do not depend on $F_{\mathrm{CH}_{4}}^{\mathrm{WPL}}$.

Values for the slope before and after applying the $\mathrm{H}_{2} \mathrm{O}$ corrections are given in Table 4 . Before applying the $\mathrm{H}_{2} \mathrm{O}$ correction, the slopes differ from zero and the difference from zero is statistically significant. This was expected since the fluxes were still affected by density and spectroscopic effects and the difference should be related to $F_{\mathrm{CH}_{4}}^{\mathrm{WPL}}$. If the slope is small before the $\mathrm{H}_{2} \mathrm{O}$ correction is applied, it can be said that for that setup the effect of $\mathrm{H}_{2} \mathrm{O}$ on $\mathrm{CH}_{4}$ fluxes is small. This presumably can be explained by enhanced phase and amplitude shifts of the $\mathrm{H}_{2} \mathrm{O}$ signal in that particular setup which diminish the effect of $\mathrm{H}_{2} \mathrm{O}$ on $\mathrm{CH}_{4}$ flux measurements. This is the case for instance for DLT-100, for which the slope was $-0.181 \pm 0.140$ before applying any $\mathrm{H}_{2} \mathrm{O}$ corrections.

For the QCL no density or spectroscopic corrections were applied, because the gas analyser was connected to a drier. In theory, the differences between G2311-f and QCL $\mathrm{CH}_{4}$ fluxes should not correlate with $F_{\mathrm{CH}}^{\mathrm{WPL}}$, since both should be free from any interference from $\mathrm{H}_{2} \mathrm{O}$. This is supported by the small slope derived for the QCL of $-0.035 \pm 0.245$ (Table 4). Thus, it can be said that the drier connected to the QCL worked well.

After applying the $\mathrm{H}_{2} \mathrm{O}$ corrections the slopes were generally closer to zero, which implies that the corrections modified the $\mathrm{CH}_{4}$ fluxes in the right direction. For the FGGA, the slope after applying the $\mathrm{H}_{2} \mathrm{O}$ corrections was 

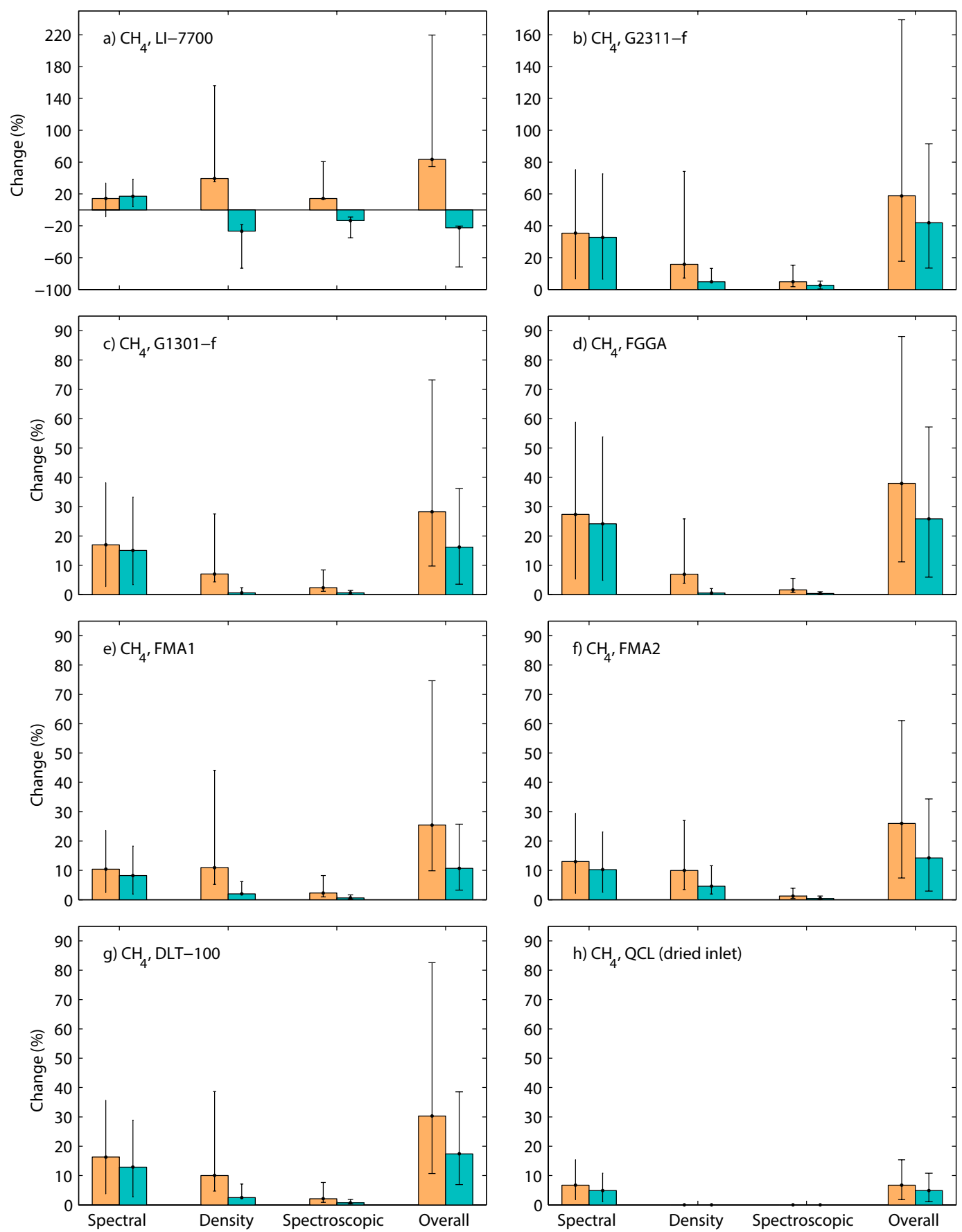

Figure 8. Change in $\mathrm{CH}_{4}$ flux after applying different corrections. The values are given as a percentage of raw uncorrected flux. Bold bars give the median and error bars give the 25 th and 75 th percentile values. Light brown bars show daytime data (sun elevation angle $>0^{\circ}$ ) and light blue bars show nighttime data (sun elevation angle $<-3^{\circ}$ ). Bars on the far right show the overall effect. Negative value means that the correction is increasing downward fluxes, positive that it is increasing upward fluxes. Note the changing scale on the $y$ axis.

$-0.026 \pm 0.047$, which is not significantly different from zero; this suggests that the coefficients obtained from Hiller et al. (2012) were applicable to the FGGA used in this study. Only the slopes for DLT-100 and FMA1 remained statistically significantly different from zero, even after correc- tion. DLT-100 fluxes were over-corrected (the slope was positive after $\mathrm{H}_{2} \mathrm{O}$ correction) and FMA1 fluxes were undercorrected (the slope was negative after $\mathrm{H}_{2} \mathrm{O}$ correction). Neither of these gas analysers measured $\mathrm{H}_{2} \mathrm{O}$ and thus external $\mathrm{H}_{2} \mathrm{O}$ measurements were used to correct their $\mathrm{CH}_{4}$ 
Table 4. Summary of the values for slope $k$ of a linear fit $\Delta F_{\mathrm{CH}_{4}}=$ $k F_{\mathrm{CH}_{4}}^{\mathrm{WPL}}$, where $\Delta F_{\mathrm{CH}_{4}}$ is the difference between fully corrected

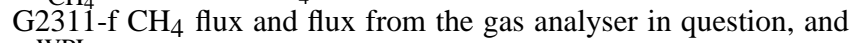
$F_{\mathrm{CH}_{4}}^{\mathrm{WP}}$ is the correction term related to density corrections (second term on the right-hand side in Eq. (5)). $\mathrm{F}_{\mathrm{CH}_{4}}^{\mathrm{WPL}}$ was calculated using $\mathrm{H}_{2} \mathrm{O}$ measured with LI-7000 and the lag time of $\mathrm{H}_{2} \mathrm{O}$ itself, meaning that the used $\mathrm{H}_{2} \mathrm{O}$ covariance was maximised for every averaging period. Values and standard errors for slope $k$ are given before and after $\mathrm{H}_{2} \mathrm{O}$ corrections (density and spectroscopic correction). In theory, after $\mathrm{H}_{2} \mathrm{O}$ corrections the slope should be zero. Symbol * highlights those values for $k$ which are significantly different from 0 at $P=95 \%$. LI-7700 is not shown, since temperature, not only $\mathrm{H}_{2} \mathrm{O}$, also affects $\mathrm{LI}-7700 \mathrm{CH}_{4}$ fluxes.

\begin{tabular}{lrr}
\hline $\begin{array}{l}\text { Gas } \\
\text { analyser }\end{array}$ & $\begin{array}{r}\text { Before } \mathrm{H}_{2} \mathrm{O} \\
\text { corrections }\end{array}$ & $\begin{array}{r}\text { After } \mathrm{H}_{2} \mathrm{O} \\
\text { corrections }\end{array}$ \\
\hline G2311-f & $-1.266 \pm 0.018^{*}$ & 0 \\
G1301-f & $-0.416 \pm 0.269^{*}$ & $0.259 \pm 0.272$ \\
FGGA & $-0.657 \pm 0.050^{*}$ & $-0.026 \pm 0.047$ \\
FMA1 & $-1.134 \pm 0.178^{*}$ & $-0.200 \pm 0.180^{*}$ \\
FMA2 & $-0.458 \pm 0.172^{*}$ & $0.116 \pm 0.177$ \\
DLT-100 & $-0.181 \pm 0.140^{*}$ & $0.846 \pm 0.140^{*}$ \\
QCL & $-0.035 \pm 0.245$ & $-0.035 \pm 0.245$ \\
\hline
\end{tabular}

fluxes. Assuming that the coefficients obtained from Hiller et al. (2012) are applicable to the DLT-100 and FMA1 used in this study, the non-zero slopes suggest that the empirical method used to parameterise the lag time difference between the $\mathrm{H}_{2} \mathrm{O}$ signal and other scalar signals (Sect. 3.4.1) was not fully successful. Moreover, different attenuation and shape of the cross-covariance function may have contributed to the miscalculation of the $\mathrm{H}_{2} \mathrm{O}$ correction (see Sect. 4.3.3 and Fig. 10). For the DLT-100 the value of the covariance of $w$ with $\mathrm{H}_{2} \mathrm{O}, \overline{w^{\prime} \chi_{v}^{\prime}}$, used in Eq. (5) appears to have been too high and for the FMA1 too small. In the case of the G1301$\mathrm{f}$, which did not measure $\mathrm{H}_{2} \mathrm{O}$ either, the method seemed to overcorrect the data since the slope was positive $(0.259)$, but the difference from zero was not statistically significant.

The above discussion deals with the systematic error in the $\mathrm{H}_{2} \mathrm{O}$ correction. Despite the fact that the correction is highly sensitive to the lag time, attenuation and the shape of the cross-covariance function, one might be tempted to use external $\mathrm{H}_{2} \mathrm{O}$ measurements to correct $\mathrm{CH}_{4}$ fluxes if the $\mathrm{H}_{2} \mathrm{O}$ obtained from the $\mathrm{CH}_{4}$ analyser is noisy. Uncertainties in $\overline{w^{\prime} \chi_{c}^{\prime}}$ and $\overline{w^{\prime} \chi_{v}^{\prime}}$ calculated with the data from FGGA were estimated based on Finkelstein and Sims (2001), and this uncertainty is assumed to be the total uncertainty of $\overline{w^{\prime} \chi_{v}^{\prime}}$. By applying error propagation to Eq. (5) we can estimate how much the noise in $\overline{w^{\prime} \chi_{v}^{\prime}}$ is affecting the precision of $\mathrm{CH}_{4}$ fluxes when the density and spectroscopic corrections are done. Relative uncertainty of FGGA $\mathrm{CH}_{4}$ fluxes is increased from 24.3 to $24.4 \%$ after applying the $\mathrm{H}_{2} \mathrm{O}$ corrections. If the uncertainty in $\overline{w^{\prime} \chi_{v}^{\prime}}$ is artificially doubled, then the relative $\mathrm{CH}_{4}$ flux uncertainty is increased by $0.4 \%$. Thus it can

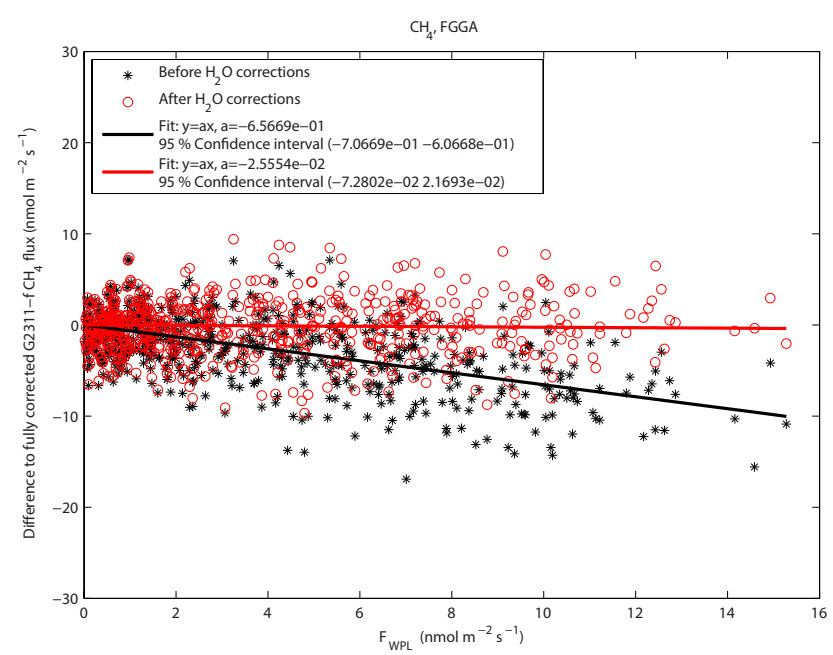

Figure 9. Difference between FGGA $\mathrm{CH}_{4}$ fluxes and fully corrected $\mathrm{G} 2311-\mathrm{f}_{4}$ fluxes before (black markers) and after (red markers) $\mathrm{H}_{2} \mathrm{O}$ corrections are applied to FGGA $\mathrm{CH}_{4}$ data. $F_{\text {WPL }}$ was calculated with $\mathrm{H}_{2} \mathrm{O}$ covariance, $\overline{w^{\prime} \chi_{v}^{\prime}}$, maximised.

be said that use of noisy $\mathrm{H}_{2} \mathrm{O}$ data in the $\mathrm{H}_{2} \mathrm{O}$ corrections does not compromise the precision of $\mathrm{CH}_{4}$ fluxes. Moreover, if the $\mathrm{CH}_{4}$ analyser also measures $\mathrm{H}_{2} \mathrm{O}$ these measurements should be used to correct the $\mathrm{CH}_{4}$ data no matter how noisy the $\mathrm{H}_{2} \mathrm{O}$ signal is, rather than external $\mathrm{H}_{2} \mathrm{O}$ data.

\subsubsection{Correcting $\mathrm{CH}_{4}$ fluxes without concurrent $\mathrm{H}_{2} \mathrm{O}$ measurements}

Figure 10 exemplifies the problem of using external $\mathrm{H}_{2} \mathrm{O}$ measurements in two contrasting situations: one with low and one with high latent heat flux. The cross-correlation between $\mathrm{CH}_{4}$ (FGGA) and $w$, and between $\mathrm{H}_{2} \mathrm{O}$ (FGGA) and $w$ both peak at different lag times even though the gases are measured with the same sampling line and instrument. The difference is caused by the sorption/desorption of $\mathrm{H}_{2} \mathrm{O}$ on the internal walls of the sampling tube and filters. The $\mathrm{H}_{2} \mathrm{O}$ cross-covariances shown in these plots are normalised with the values that should be used in Eq. (5) for correcting FGGA $\mathrm{CH}_{4}$ fluxes (black dots in the plots). Thus, for instance, if in these situations the covariances between $\mathrm{H}_{2} \mathrm{O}$ (FGGA) and $w$ are maximised and then used in the $\mathrm{H}_{2} \mathrm{O}$ corrections, the corrections are overestimated by $132 \%$ (left plot in Fig. 10) and $21 \%$ (right plot in Fig. 10). Moreover, the two $\mathrm{H}_{2} \mathrm{O}$ cross-covariances (LI-7000 and FGGA) shown in both plots have different degrees of attenuation, the FGGA $\mathrm{H}_{2} \mathrm{O}$ cross-covariance being more attenuated, and the shape of the cross-covariance is affected by the tube effects. The FGGA $\mathrm{H}_{2} \mathrm{O}$ cross-covariance functions are wider and the peaks not as sharp as in the LI-7000 $\mathrm{H}_{2} \mathrm{O}$ cross-covariances. In order to correct successfully $\mathrm{CH}_{4}$ fluxes using $\mathrm{H}_{2} \mathrm{O}$ covariance measurements, all three effects (lag time, attenuation and shape of the cross-covariance) induced on $\mathrm{H}_{2} \mathrm{O}$ by the sampling 

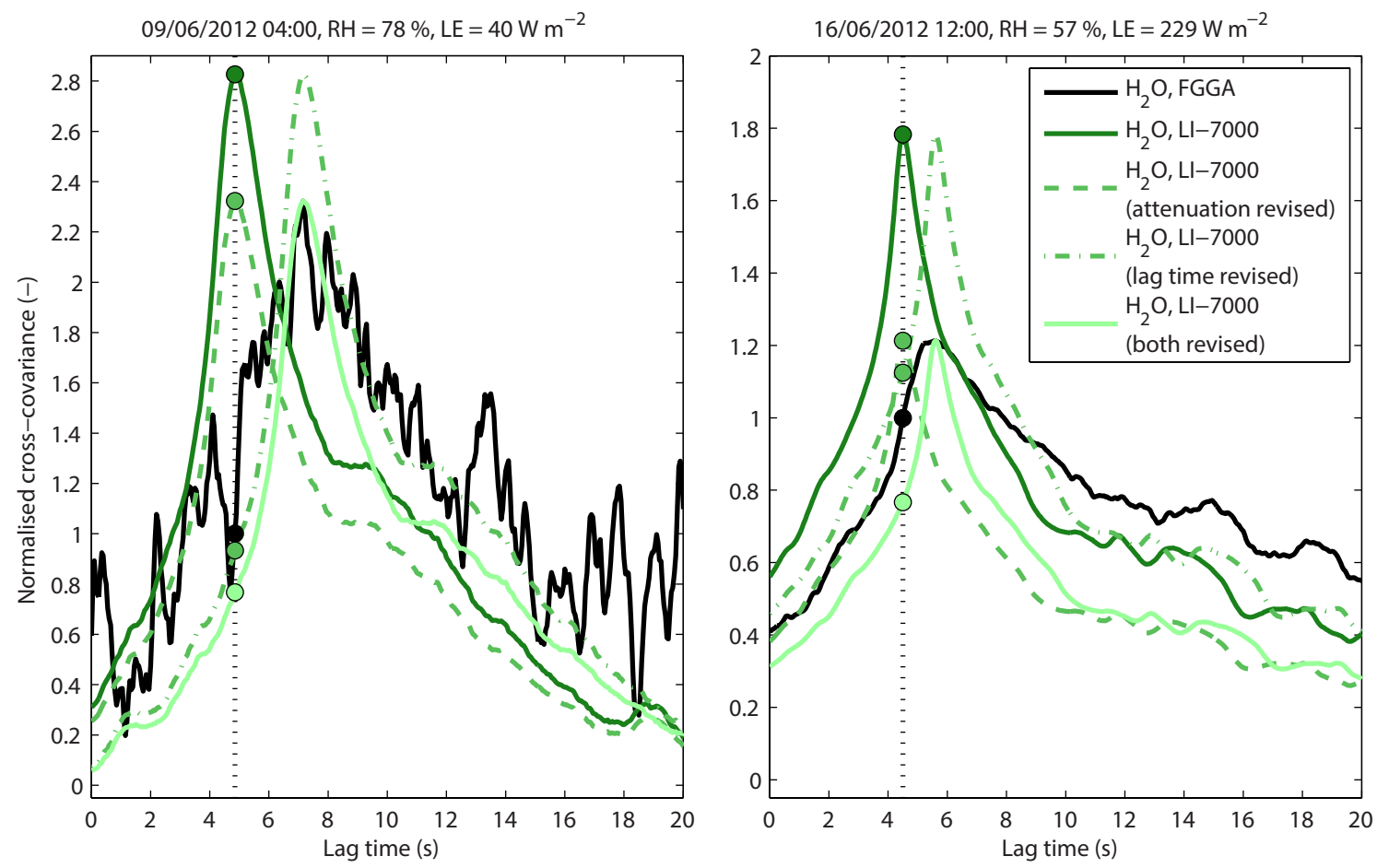

Figure 10. Two examples of cross-covariances between $w$ and $\mathrm{H}_{2} \mathrm{O}$ (FGGA) and $\mathrm{H}_{2} \mathrm{O}$ (LI-7000). Location (lag time) and amplitude (attenuation) of $\mathrm{H}_{2} \mathrm{O}$ (LI-7000) cross-covariance are adjusted in order to replicate $\mathrm{H}_{2} \mathrm{O}$ (FGGA) cross-covariance. $\mathrm{H}_{2} \mathrm{O}$ cross-covariances were normalised with the values that should be used in Eq. (5) in order to illustrate the magnitude of the relative error made in density and spectroscopic corrections (Eq. 5) if different values for $\overline{w^{\prime} \chi_{v}^{\prime}}$ are used. The dots show the values which would be used in the correction (Eq. 5). Vertical dotted lines show the $\mathrm{CH}_{4}$ lag time.

line must be properly taken into account. If the $\mathrm{H}_{2} \mathrm{O}$ is measured with the same instrument as the $\mathrm{CH}_{4}$; this is achieved by calculating the $\mathrm{H}_{2} \mathrm{O}$ covariance with the same time lag that is used for calculating the $\mathrm{CH}_{4}$ flux. If $\mathrm{H}_{2} \mathrm{O}$ is measured by an external instrument, the effects need to be estimated.

In order to study how sensitive the $\mathrm{H}_{2} \mathrm{O}$ corrections are to the effects of the sampling line on measured $\mathrm{H}_{2} \mathrm{O}$, FGGA $\mathrm{CH}_{4}$ fluxes were corrected with LI-7000 $\mathrm{H}_{2} \mathrm{O}$ measurements and then compared with the correction calculated with the internal $\mathrm{H}_{2} \mathrm{O}$ measurements and internal $\mathrm{CH}_{4}$ lag time. The LI-7000 $\mathrm{H}_{2} \mathrm{O}$ covariance used in Eq. (5) was modified with four different methods (see Fig. 10): the covariance between LI-7000 $\mathrm{H}_{2} \mathrm{O}$ and $w$ was maximised and then used in Eq. (5) (no revision), LI-7000 $\mathrm{H}_{2} \mathrm{O}$ cross-covariance maximum was adjusted to be the same as the FGGA $\mathrm{H}_{2} \mathrm{O}$ crosscovariance maximum (attenuation revised), LI-7000 $\mathrm{H}_{2} \mathrm{O}$ lag time was revised to match the FGGA $\mathrm{H}_{2} \mathrm{O}$ lag time (lag time revised), and both, attenuation and lag time, are revised (both revised). A comparison between these four methods and the reference correction calculated using insitu FGGA $\mathrm{H}_{2} \mathrm{O}$ measurements is shown in Fig 11. With no revision applied to LI-7000 $\mathrm{H}_{2} \mathrm{O}$ data (i.e. the $\mathrm{H}_{2} \mathrm{O}$ covariance is calculated from the LI-7000 data choosing the time lag that maximises the covariance for that sen- sor), the correction is clearly overestimated, by approximately $2.85 \mathrm{nmol} \mathrm{m}^{-2} \mathrm{~s}^{-1}$ (74\% overestimation), when LE was above $150 \mathrm{~W} \mathrm{~m}^{-2}$. If the attenuation is revised this error decreases to $1.07 \mathrm{nmol} \mathrm{m}^{-2} \mathrm{~s}^{-1}$ ( $25 \%$ overestimation), if the lag time is revised the error is $0.24 \mathrm{nmol} \mathrm{m}^{-2} \mathrm{~s}^{-1}(5 \%$ overestimation) and if both are revised the correction becomes underestimated by $0.88 \mathrm{nmol} \mathrm{m}^{-2} \mathrm{~s}^{-1}(21 \%$ underestimation). By revising both, attenuation and lag time, the results were worse than just by altering the lag time. This stems from the fact that the shape of the $\mathrm{H}_{2} \mathrm{O}$ cross-covariance is also altered, which was not accounted for here.

Systematic bias in the daily cycle of $\mathrm{FGGA} \mathrm{CH}_{4}$ fluxes in these four cases is shown in Fig. 12. The daytime $\mathrm{CH}_{4}$ fluxes are overestimated in the "No revision" case (Fig. 12a) and in the "Attenuation revised" case (Fig. 12b). This is in line with Fig. 11a and b, since at daytime the latent heat flux is high and according to Fig. $11 \mathrm{a}$ and $\mathrm{b}$ this also increases the bias in the correction. In the "Lag time revised" case no clear bias in the daily cycle can be seen, whereas in the "Both revised" case daytime $\mathrm{CH}_{4}$ fluxes are underestimated.

The fact that $\mathrm{H}_{2} \mathrm{O}$ corrections are highly sensitive to the lag time used in calculating $\overline{w^{\prime} \chi_{v}^{\prime}}$ results from the shape of cross-covariance between $w$ and $\chi_{v}$. The cross-covariance between $w$ and $\chi_{v}$ is an exponential function of the time lag 

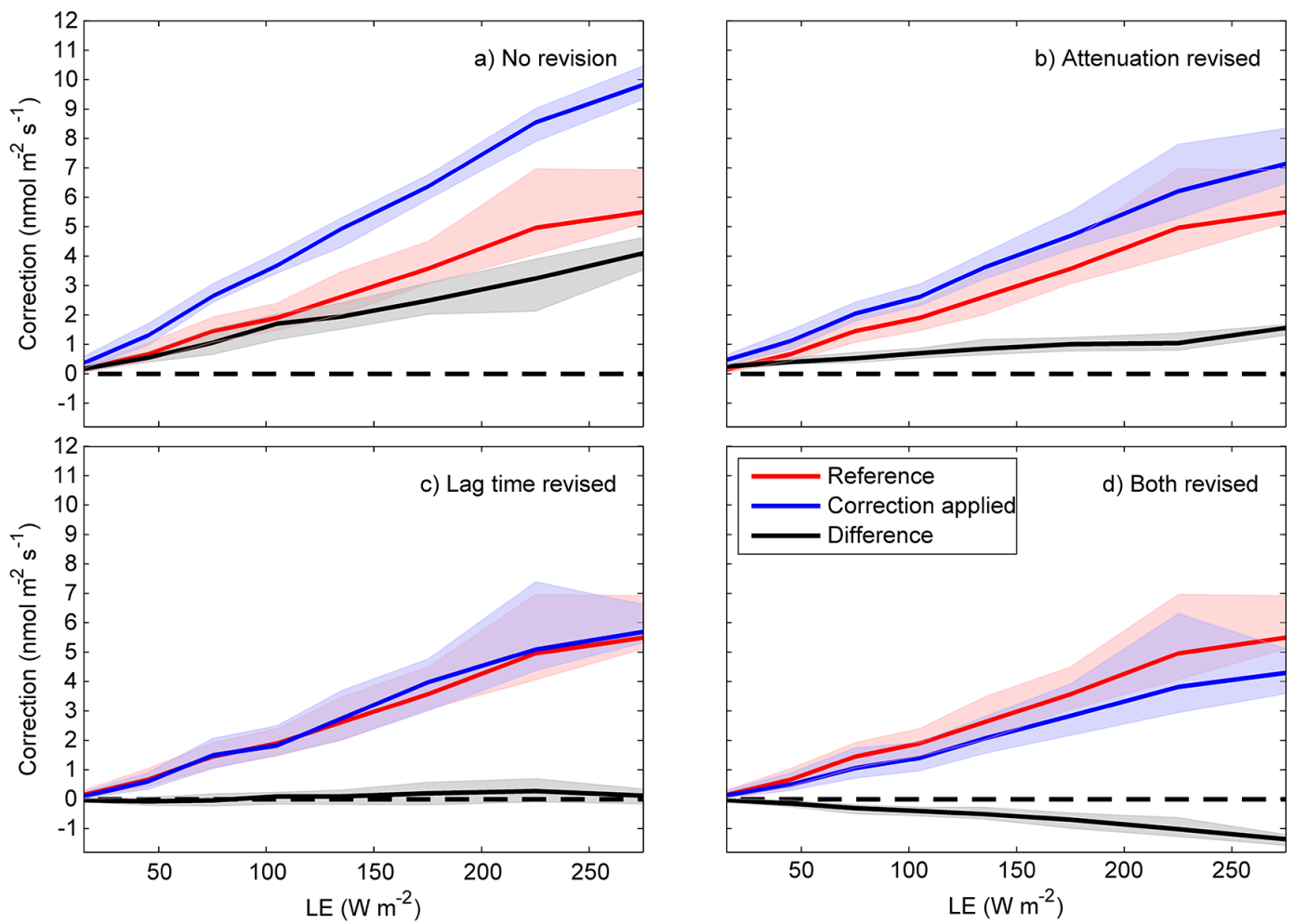

Figure 11. Combined error in density and spectroscopic corrections as a function of latent heat flux if external $\mathrm{H}_{2} \mathrm{O}$ measurements are used in Eq. (5). FGGA CH 4 fluxes were corrected with LI-7000 $\mathrm{H}_{2} \mathrm{O}$ measurements (blue colour) and with FGGA-internal $\mathrm{H}_{2} \mathrm{O}$ measurements (red colour) which yield correct values and are shown for comparison. The difference between these two, i.e. error in the correction using external $\mathrm{H}_{2} \mathrm{O}$, is plotted with black colour. The lines show medians and the areas show interquartile range around the medians. (a) The correction is calculated by maximising LI-7000 $\overline{w^{\prime} \chi_{v}^{\prime}}$. (b) Maximum of LI-7000 $\overline{w^{\prime} \chi_{v}^{\prime}}$ is adjusted to match the maximum of FGGA $\overline{w^{\prime} \chi_{v}^{\prime}}$. (c) Lag time of LI-7000 $\overline{w^{\prime} \chi_{v}^{\prime}}$ is adjusted to match the lag time of FGGA $\overline{w^{\prime} \chi_{v}^{\prime}}$. (d) Both lag time and maximum of LI-7000 $\overline{w^{\prime} \chi_{v}^{\prime}}$ are set to match FGGA $\overline{w^{\prime} \chi_{v}^{\prime}}$. Data measured during the whole campaign (635 points) were divided into 8 latent heat flux bins before plotting. The dashed lines highlight the zero line. See also Fig. 10 for examples from two contrasting averaging periods.

between the time series and thus the error in the correction increases exponentially when error in the lag increases.

\subsection{Agreement between flux estimates}

After corrections have been applied as well as possible, all the instruments agreed relatively well with the median $\mathrm{CH}_{4}$ flux (Table 5). The slopes of the linear fits with this median flux were between 1.090 (G1301-f) and 0.997 (FGGA) and the intercepts were acceptable, ranging from -6.835 (LI7700) to $2.997 \mathrm{nmol} \mathrm{m}^{-2} \mathrm{~s}^{-1}$ (DLT-100). The values of the correlation coefficient were close to 1 , which implies that all flux results are highly correlated. The LI-7700 had the highest value of root mean square error (RMSE); this implies that it had the highest scatter in $\mathrm{CH}_{4}$ fluxes. This might be at least partly caused by the LI-7700 data-logging problem and partly caused by the fact that it is an open-path gas analyser and that the open sampling cell was vulnerable to disturbances which might appear as high variation in the fluxes. Of the closed-path instruments, FMA2, QCL and G1301-f gave the highest values for RMSE.
Table 5. Agreement between $\mathrm{CH}_{4}$ fluxes obtained from different instruments and median $\mathrm{CH}_{4}$ flux from all instruments. $221 \mathrm{CH}_{4}$ flux data points when all instruments were working were used in the analysis. For G1301-f only 139 points were used due to the short operating time of the instrument. Only periods when all $\mathrm{CH}_{4}$ fluxes had the quality flag 0 or 1 and the difference between sensible heat fluxes from the two anemometers was smaller than $40 \mathrm{~W} \mathrm{~m}^{-2}$ were used. LI-7700 data are affected by an external data-logging problem which is not caused by the analyser.

\begin{tabular}{lrrrr}
\hline $\begin{array}{l}\text { Gas } \\
\text { analyser }\end{array}$ & Slope & $\begin{array}{r}\text { Intercept } \\
(\mathrm{nmol} \\
\left.\mathrm{m}^{-2} \mathrm{~s}^{-1}\right)\end{array}$ & $\begin{array}{r}\text { RMSE } \\
(\mathrm{nmol} \\
\left.\mathrm{m}^{-2} \mathrm{~s}^{-1}\right)\end{array}$ & $\begin{array}{r}\text { Correlation } \\
\text { coefficient } r\end{array}$ \\
\hline LI-7700 & 1.014 & -6.835 & 16.554 & 0.879 \\
G2311-f & 1.003 & 1.128 & 5.573 & 0.986 \\
G1301-f & 1.090 & -2.489 & 6.386 & 0.989 \\
FGGA & 0.997 & 1.015 & 4.782 & 0.990 \\
FMA1 & 1.029 & -2.076 & 5.642 & 0.986 \\
FMA2 & 1.058 & -0.303 & 8.001 & 0.974 \\
DLT-100 & 1.055 & 2.997 & 5.742 & 0.987 \\
QCL & 1.000 & -1.652 & 7.092 & 0.977 \\
\hline
\end{tabular}



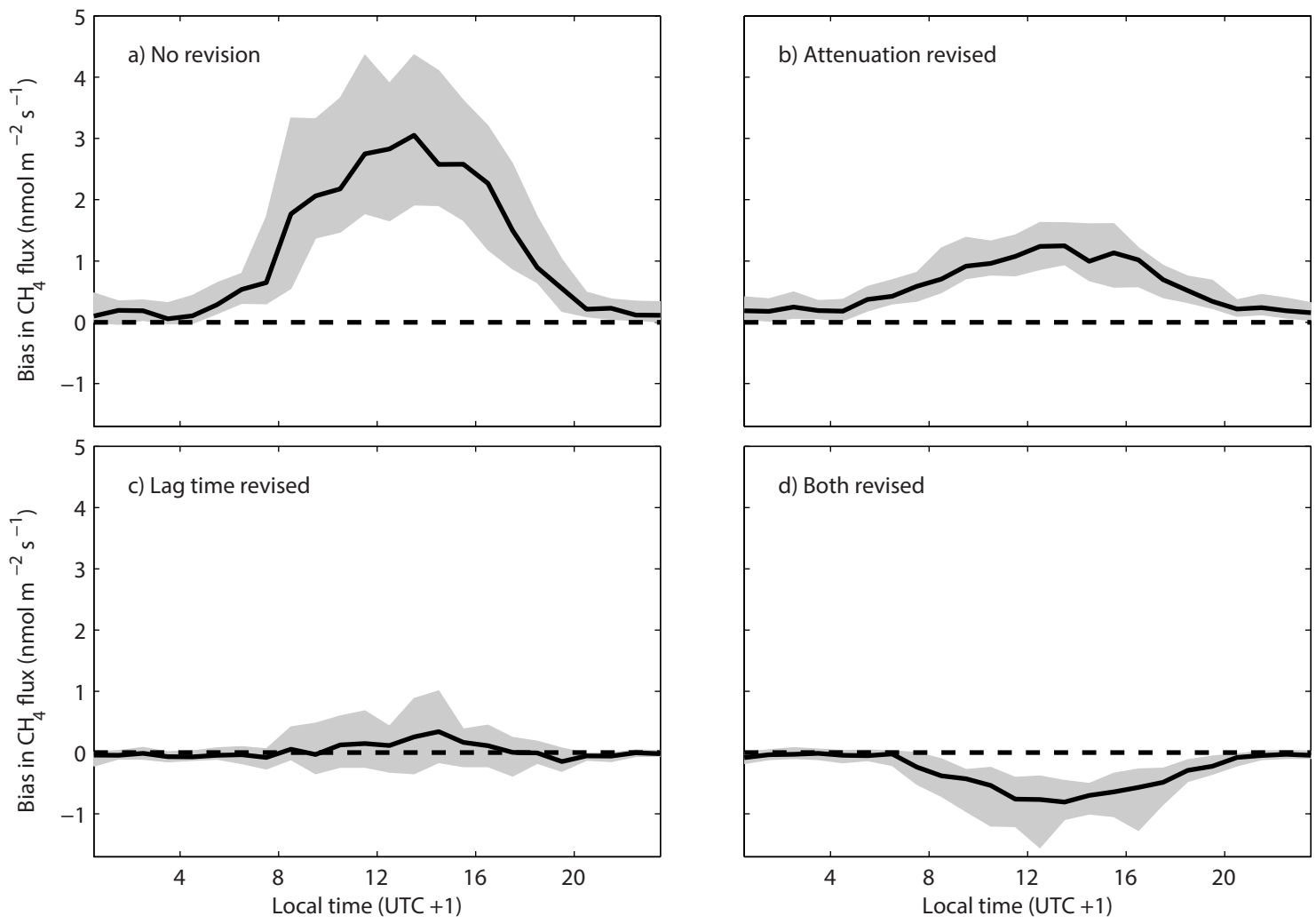

Figure 12. Daily course of the systematic bias observed in $\mathrm{FGGA} \mathrm{CH}_{4}$ flux if the density and spectroscopic corrections (Eq. 5) are made with external $\mathrm{H}_{2} \mathrm{O}$ measurements, i.e. LI-7000 $\mathrm{H}_{2} \mathrm{O}$ measurements. The lines show medians and the areas show the interquartile range around the medians. (a) The correction is calculated by maximising LI-7000 $\overline{w^{\prime} \chi_{v}^{\prime}}$. (b) Maximum of LI-7000 $\overline{w^{\prime} \chi_{v}^{\prime}}$ is adjusted to match the maximum of FGGA $\overline{w^{\prime} \chi_{v}^{\prime}}$. (c) Lag time of LI-7000 $\overline{w^{\prime} \chi_{v}^{\prime}}$ is adjusted to match the lag time of FGGA $\overline{w^{\prime} \chi_{v}^{\prime}}$. (d) Both lag time and maximum of LI-7000 $\overline{w^{\prime} \chi_{v}^{\prime}}$ are set to match FGGA $\overline{w^{\prime} \chi_{v}^{\prime}}$. Data measured during the whole campaign (635 points) were used. The dashed lines highlight the zero line. See also Fig. 10 for examples from two contrasting averaging periods.

Despite the good agreement between the $\mathrm{CH}_{4}$ fluxes shown in Table 5, there seems to have been a systematic bias between the different instruments, which is revealed by the cumulative sums shown in Fig. 13 (left plot). Most of the flux time series gave a value around $360 \mathrm{mg} \mathrm{m}^{-2}$ for the cumulative $\mathrm{CH}_{4}$ emission during the 13-day period shown in the plot; however, three time series deviated most from this value: FMA1 and QCL derived about $330 \mathrm{mg} \mathrm{m}^{-2}$ and the DLT-100 $399 \mathrm{mg} \mathrm{m}^{-2}$ for the cumulative sum.

Cumulative $\mathrm{CH}_{4}$ emissions from three gas analysers (G2311-f, FGGA and FMA2) agreed best. For these three analysers the $\mathrm{H}_{2} \mathrm{O}$ corrections were done using internal $\mathrm{H}_{2} \mathrm{O}$ measurements and thus it can be assumed that the corrections were done accurately. Two out of the three time series which diverged most from the mean (DLT-100 and FMA1) were corrected with external $\mathrm{H}_{2} \mathrm{O}$ measurements, which suggests that the differences in cumulative $\mathrm{CH}_{4}$ emissions could have been caused by the $\mathrm{H}_{2} \mathrm{O}$ corrections. To test this, the $\mathrm{H}_{2} \mathrm{O}$ corrections were adjusted so that the slopes in the column on the right in Table 4 became zero, meaning that a time series $-k F_{\mathrm{CH}_{4}}^{\mathrm{WPL}}$, where $k$ is the slope, was added to the fluxes. Af- ter the adjustment the difference between the G2311- $\mathrm{f} \mathrm{CH}_{4}$ flux and other $\mathrm{CH}_{4}$ fluxes no longer depended on $F_{\mathrm{CH}_{4}}^{\mathrm{WPL}}$. Cumulative $\mathrm{CH}_{4}$ emissions after adjusting the $\mathrm{H}_{2} \mathrm{O}$ corrections are shown on the right in Fig. 13. The agreement is better than before adjustment and now the values range from $335 \mathrm{mg} \mathrm{m}^{-2}$ (QCL) to $367 \mathrm{mg} \mathrm{m}^{-2}$ (G2311-f). Thus the differences seen before the adjustment can at least partly be attributed to miscalculated $\mathrm{H}_{2} \mathrm{O}$ corrections.

Monthly values were calculated by computing mean values for the $\mathrm{CH}_{4}$ fluxes during 12 to 25 June (the same time period as in Fig. 13) and then multiplying the mean values by the length of the month June (Fig. 14). Figure 14 shows the same pattern as Fig. 13: the DLT-100 initially gave higher fluxes and the FMA1 gave lower fluxes than all the analysers on average; however, the difference decreased if the $\mathrm{H}_{2} \mathrm{O}$ corrections were set to match the G2311-f. For the DLT-100 the difference between fluxes calculated with original and adjusted $\mathrm{H}_{2} \mathrm{O}$ correction on a monthly scale was approximately $0.1 \mathrm{~g}\left(\mathrm{CH}_{4}\right) \mathrm{m}^{-2}$, which is $8 \%$ of the monthly $\mathrm{CH}_{4}$ emission observed on average. These results highlight the importance of proper $\mathrm{H}_{2} \mathrm{O}$ corrections, especially for calculating 

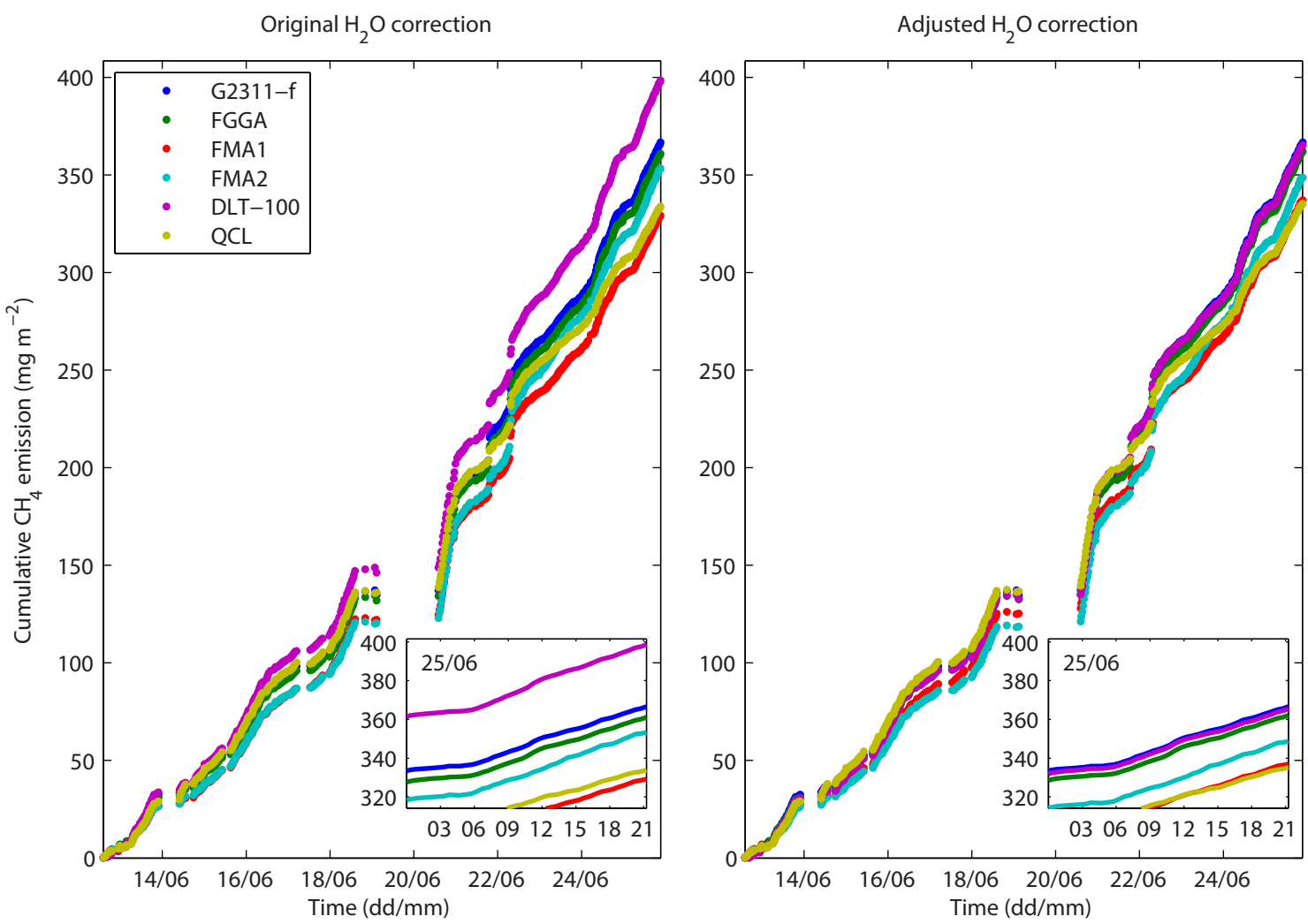

Figure 13. Cumulative sums of $\mathrm{CH}_{4}$ fluxes during a part of the campaign (from 12 to 25 June). The time series are not gap filled and they all contain the same number of points. The left plot shows fluxes calculated with the original $\mathrm{H}_{2} \mathrm{O}$ corrections and the right plot shows cumulative $\mathrm{CH}_{4}$ fluxes after adjusting the $\mathrm{H}_{2} \mathrm{O}$ corrections with the slopes given in the right in Table 4 , in other words by adding $-k F_{\mathrm{CH}_{4}}^{\mathrm{WPL}}$, where $k$ is the slope. Thus, after this adjustment the differences between $\mathrm{G} 2311-\mathrm{f}_{\mathrm{CH}_{4}}$ fluxes and other $\mathrm{CH}_{4}$ fluxes do not depend on $F_{\mathrm{CH}_{4}}^{\mathrm{WPL}}$. Data from LI-7700 and G1301-f are not shown. The insets show a close-up of the last day.

long-term $\mathrm{CH}_{4}$ balances. As the absolute value of the $\mathrm{H}_{2} \mathrm{O}$ corrections depends on the magnitude of the latent heat flux, the corrections are significant in locations where latent heat fluxes are large and $\mathrm{CH}_{4}$ fluxes are low.

The slightly smaller cumulative $\mathrm{CH}_{4}$ emissions observed with QCL, FMA2 and FMA1 than with the other three gas analysers cannot be explained by the use of two anemometers: the anemometer which was accompanying the three analysers mentioned above (METEK2) gave on average a $4 \%$ larger value for turbulence intensity $\left(\sigma_{w} / U\right)$ and $2 \%$ larger value for sensible heat flux than the other anemometer (METEK1). This implies that the fluxes measured with METEK2 should not be underestimated compared to fluxes measured with METEK1.

\section{Discussion}

All three previously published $\mathrm{CH}_{4}$ flux inter-comparison studies (Detto et al., 2011; Peltola et al., 2013; Tuzson et al., 2010) showed relatively good correspondence between measured $\mathrm{CH}_{4}$ fluxes. Detto et al. (2011) compared the per- formance of LI-7700 against two LGR analysers (FMA and FGGA) and they showed that minimum detectable flux was similar from all instruments and the fluxes from LI-7700 agreed with the closed-path LGR $\mathrm{CH}_{4}$ fluxes during both low and high flux periods, although there was scatter in the results. They also concluded that using a low capacity pump instead of a high capacity version for the closed-path LGR analyser will add uncertainty to the fluxes. Tuzson et al. (2010) compared the results from QCL and FMA gas analysers. In that study artificial $\mathrm{CH}_{4}$ flux was created in the prevailing wind direction and both instruments were able to quantify the artificial flux accurately. Peltola et al. (2013) presented results from $\mathrm{CH}_{4}$ flux measurements at a boreal fen during summer 2010. In that study four $\mathrm{CH}_{4}$ gas analysers were deployed (FMA, G1301-f, TGA-100A (Campbell Scientific Inc., USA) and an early prototype version of LI7700). Excellent agreement between FMA and G1301-f was shown, whereas LI-7700 and TGA-100A produced slightly more scattered results. Less than $0.5 \mathrm{~g}\left(\mathrm{CH}_{4}\right) \mathrm{m}^{-2}$ difference (4\% relative difference) was found in the cumulative sums of the gap-filled $\mathrm{CH}_{4}$ flux data over 6 months from FMA, G1301-f and TGA-100A. Although all these studies provide 


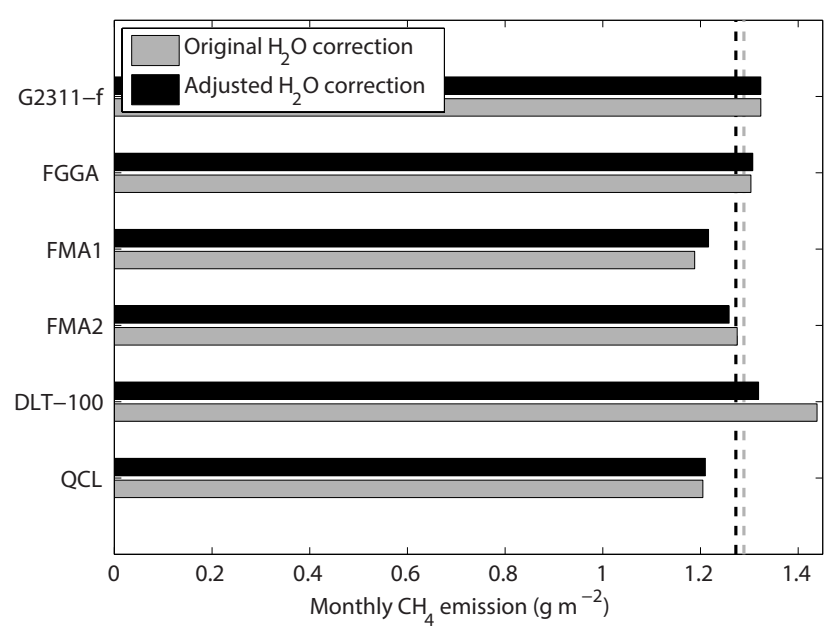

Figure 14. Monthly $\mathrm{CH}_{4}$ emissions estimated from mean $\mathrm{CH}_{4}$ fluxes observed during part of the campaign (from 12 to 25 June). Data corrected with the original $\mathrm{H}_{2} \mathrm{O}$ correction are shown with grey bars and with the adjusted $\mathrm{H}_{2} \mathrm{O}$ corrections $\left(-k F_{\mathrm{CH}_{4}}^{\mathrm{WPL}}\right.$ added to the fluxes) are shown with black bars. Vertical dashed lines show the mean values.

valuable knowledge on the relative performance of the instruments tested, they do not include a comprehensive set of $\mathrm{CH}_{4}$ gas analysers and thus our study with eight $\mathrm{CH}_{4}$ instruments contains important information for the scientific community.

One of the main aims in running an eddy covariance site and measuring greenhouse gas fluxes is to obtain monthly, annual or even decennial GHG budgets. Calculation of longterm budgets requires high data coverage in order to minimize the need for gap filling. Typically, open-path instruments, such as the LI-7700 used in this study, produce less flux data than closed-path devices due to the vulnerability of the open measurement cell to the elements. Data gaps often occur under certain circumstances, such as rainy periods or episodes with snow. As a consequence, when using openpath instruments, it is difficult to study how the flux levels react to precipitation. This complicates gap-filling during these episodes. Applicability of an analyser for long-term studies is also hampered if constant maintenance is needed (filter replacement, liquid nitrogen is needed for cooling the laser and/or detector, laser tuning, cleaning of measurement cell mirrors etc.), analyser drifts significantly or if the analyser malfunctions frequently and needs to be taken away from the measurement site for repair. However, due to the fairly short length of our study, we cannot conclude which one of the tested analysers is the most suitable for long-term field application, for that the reader is referred to Peltola et al. (2013) and Detto et al. (2011).

It was shown in Sect. 4.2 that Picarro instruments G2311$\mathrm{f}$ and G1301-f are superior to the other instruments tested in terms of signal noise, although the low noise estimate for G2311-f data could be partially explained by the in- strument's low measurement frequency during our experiment. For some LGR analysers, the noise responded to cell temperature and to a lesser extent to cavity ringdown time. (The newer gas analysers by LGR, so-called enhanced performance or EP models, control cell temperature more rigorously and this problem may at least partly be solved; however, this could not be verified in this study since no enhanced performance models were used.) As for the QCL, the higher noise level is typical of this older pulsed laser system. Newer QCL systems use continuous wave lasers and show significantly lower white noise levels. Unfortunately, such a system was not yet available for this campaign.

Noise in the signal makes the data analysis more difficult. For instance, spectral analysis of the data is difficult since parts of the spectra are covered by white noise. Also, assessing high-frequency attenuation of the signal becomes difficult if the measurements and the calculated cospectra are noisy; nevertheless, frequency ranges that contribute the most to the turbulent exchange are well resolved by all instruments (Figs. 6 and 7). Moreover, the noise in the data increases the random uncertainty of fluxes. However, the flux uncertainty caused by noise in $\mathrm{CH}_{4}$ data is of the order of $1 \mathrm{nmol} \mathrm{m}^{-2} \mathrm{~s}^{-1}$ (Fig. 4), whereas the fluxes measured during this study were at least ten times larger and thus even the relatively noisy QCL signal did not compromise the use of the measurements. In addition, for these instruments and the magnitude of the fluxes at the site, most of the flux random uncertainty originates from one-point sampling of the flux (Businger, 1986; Kroon et al., 2010) and not from instrumental noise. The sampling error is an inherent property of eddy covariance measurements which cannot be minimised by instrument selection or design.

All $\mathrm{CH}_{4}$ flux time series were corrected with commonly used methods. The magnitudes of the corrections (Fig. 8) are measurement site and setup specific and should be only thought of as indicative; in any case, they can be compared with each other to find out which analyser needs large corrections. As pointed out by Detto et al. (2011) and Peltola et al. (2013), the density and spectroscopic corrections are much larger for open-path LI-7700 than for the closed-path devices due to the additional contribution from unattenuated temperature fluctuations. Large corrections are not problematic as long as the sensible and latent heat fluxes used in density and spectroscopic corrections are measured accurately. However, any bias in these fluxes will also bias the $\mathrm{CH}_{4}$ fluxes, especially where $\mathrm{CH}_{4}$ fluxes are small. Usually, sensible and latent heat fluxes can exhibit significant diurnal patterns and thus miscalculated density and/or spectroscopic corrections can cause a false daily cycle in the $\mathrm{CH}_{4}$ flux (see Fig. 12) which might lead to misinterpretation. This is especially problematic if measurements are done at locations where small $\mathrm{CH}_{4}$ fluxes are measured with large sensible and latent heat fluxes. In such conditions, the corrections are large relative to the real flux (cf. Smeets et al., 2009). This problem is relevant for all analysers, but especially open-path 
instruments and those closed-path devices that do not measure $\mathrm{H}_{2} \mathrm{O}$ simultaneously. As shown in Sect. 4.3.2, estimating the $\mathrm{H}_{2} \mathrm{O}$ effect on the measured $\mathrm{CH}_{4}$ flux without any knowledge of how the measurement system alters $\mathrm{H}_{2} \mathrm{O}$ fluctuations will most likely lead to miscalculated corrections, and may even cause an erroneous daily cycle in $\mathrm{CH}_{4}$ fluxes (see Fig. 12) and overall bias the $\mathrm{CH}_{4}$ fluxes. One approach to minimising this problem is the usage of one main sampling line for two analysers: one which measures $\mathrm{CH}_{4}$ (e.g. FMA) and one which measures $\mathrm{H}_{2} \mathrm{O}$ (e.g. LI-7000), and then using the measured $\mathrm{H}_{2} \mathrm{O}$ to correct $\mathrm{CH}_{4}$ data. For FMA1 such a measurement setup was used in this study, nevertheless the $\mathrm{H}_{2} \mathrm{O}$ corrections were still underestimated (Table 4). This might have been caused by the use of different filters in FMA1 and LI-7000 sampling lines (Table 1) and their different contribution to $\mathrm{H}_{2} \mathrm{O}$ phase and amplitude shifts. Alternatively, one can determine the $\mathrm{H}_{2} \mathrm{O}$ effects in the sampling line before it is deployed in the field (cf. Querino et al., 2011), or the air sample may be dried; however, none of the driers completely removes $\mathrm{H}_{2} \mathrm{O}$ from the air samples. There is always some residual $\mathrm{H}_{2} \mathrm{O}$ left, although it does not necessarily significantly affect the $\mathrm{CH}_{4}$ fluxes. Thus if possible one should use gas analysers which measure $\mathrm{CH}_{4}$ and $\mathrm{H}_{2} \mathrm{O}$ in situ or alternatively open-path analysers for which the WPL and spectroscopic corrections can be made using atmospheric sensible and latent fluxes. All the new $\mathrm{CH}_{4}$ closed-path gas analysers also measure $\mathrm{H}_{2} \mathrm{O}$, and thus this problem is more related to the use of slightly older models such as the FMA.

\section{Summary and conclusions}

Eight fast-response $\mathrm{CH}_{4}$ gas analysers suitable for eddy covariance flux measurements were inter-compared at a Dutch agricultural site and the high-frequency data were postprocessed with up-to-date methods. The measurements were evaluated based on several parameters, such as data coverage and quality, amount of noise in the signal, magnitude and simplicity of different corrections, and the agreement of the fluxes obtained with the different instruments.
Mostly the differences in performance result from data coverage and the amount of noise in the data. For some of the slightly older instruments the fact that they did not measure $\mathrm{H}_{2} \mathrm{O}$ proved to be a challenge during data processing and a significant potential source of systematic bias in the $\mathrm{CH}_{4}$ fluxes, which amounted to around $0.1 \mathrm{~g}\left(\mathrm{CH}_{4}\right) \mathrm{m}^{-2}$ on a monthly scale and can therefore be significant at sites with small or medium $\mathrm{CH}_{4}$ fluxes. Biased time series are difficult to correct since the bias does not decrease with averaging, as in the case of random noise.

Out of the three newest gas analysers (G2311-f, FGGA and LI-7700), the G2311-f was superior to the others with respect to instrumental noise, but noise aside, the two closedpath instruments (G2311-f and FGGA) performed similarly. The performance of LI-7700 was difficult to assess due to data-logging issues with the instrument particular to our study. In any case, the analyser needed a lot more maintenance than the other analysers due to repeated contamination of the open measurement cell. However, with clean mirrors, the performance of the LI-7700 was comparable to the other new (closed-path) instruments. Thus the analyser remains a viable option for locations with limited power availability as long as it can be cleaned regularly, which can be demanding at remote locations. Also, the G1301-f performed well during the campaign, although the performance was difficult to assess fully because it was operated only a few days at the end of the campaign. However, the data obtained seemed to agree well with the FGGA and the G2311-f and instrumental noise was low.

The main conclusion is that all systems (excluding G1301f and LI-7700 due to low data coverage) agreed on the cumulative flux pattern over an episode of thirteen days within $\pm 10 \%$. At the moderate- or medium-range flux levels observed over the Cabauw fields each of these setups can deliver good data. For low flux conditions however, systems with less noise will outcompete the others. Moreover, the good agreement between cumulative $\mathrm{CH}_{4}$ emissions indicates that the selection of an instrument does not strongly bias the measured fluxes in one way or another, as long as the data are processed appropriately. 


\section{Appendix A: Derivation of Eq. (5)}

Equation (4), originally proposed by Rella (2010), can be used to correct measurements of gas $c$ for any interference from $\mathrm{H}_{2} \mathrm{O}$. The equation can be modified to be applicable to the averaged fluxes by first using Reynolds decomposition on all three time series, namely the wet and dry mole fractions of gas $c$ ( $\chi_{c}$ and $r_{c}$, respectively) and the mole fraction of $\mathrm{H}_{2} \mathrm{O}\left(\chi_{v}\right)$ :

$\overline{\chi_{c}}+\chi_{c}^{\prime}=\left(\overline{r_{c}}+r_{c}^{\prime}\right)\left(1+a \chi_{v}^{\prime}+a \overline{\chi_{v}}+2 b \chi_{v}^{\prime} \overline{\chi_{v}}+b{\overline{\chi_{v}}}^{2}+b \chi_{v}^{\prime 2}\right)$

Now if the equation above is multiplied by $w^{\prime}$ (vertical wind speed fluctuations) and the result is averaged, then

$$
\begin{aligned}
\overline{w^{\prime} \chi_{c}^{\prime}} & =a \overline{r_{c}} \overline{w^{\prime} \chi_{v}^{\prime}}+2 b \overline{r_{c} \overline{\chi_{v}}} \overline{w^{\prime} \chi_{v}^{\prime}}+\overline{w^{\prime} r_{c}^{\prime}}+a \overline{\chi_{v}} \overline{w^{\prime} r_{c}^{\prime}} \\
& +b \overline{\chi_{v}}{ }^{2} \overline{w^{\prime} r_{c}^{\prime}},
\end{aligned}
$$

where terms such as $\overline{w^{\prime} \overline{\chi_{c}}}$ yield zero by definition and thirdorder terms such as $\overline{w^{\prime} r_{c}^{\prime} \chi_{v}^{\prime}}$ are assumed to be negligible. By solving $\overline{w^{\prime} r_{c}^{\prime}}$ from the equation above and using Eq. (4) for mean values, the following equation is achieved:

$\overline{w^{\prime} r_{c}^{\prime}}=\frac{1}{1+a \overline{\chi_{v}}+b{\overline{\chi_{v}}}^{2}}\left(\overline{w^{\prime} \chi_{c}^{\prime}}-\frac{a+2 b \overline{\chi_{v}}}{1+a \overline{\chi_{v}}+b{\overline{\chi_{v}}}^{2}} \overline{\chi_{c}} \overline{w^{\prime} \chi_{v}^{\prime}}\right)$.

Next the second term on the right-hand side within the parentheses is separated into density and spectroscopic parts:

$$
\begin{aligned}
\overline{w^{\prime} r_{c}^{\prime}} & =\frac{1}{1+a \overline{\chi_{v}}+b{\overline{\chi_{v}}}^{2}}\left(\overline{w^{\prime} \chi_{c}^{\prime}}+\frac{\overline{\chi_{c}}}{1-\overline{\chi_{v}}} \overline{w^{\prime} \chi_{v}^{\prime}}\right. \\
& \left.-\frac{a+2 b \overline{\chi_{v}}-b{\overline{\chi_{v}}}^{2}+1}{\left(1+a \overline{\chi_{v}}+b{\overline{\chi_{v}}}^{2}\right)\left(1-\overline{\chi_{v}}\right)} \overline{\bar{\chi}_{c}} \overline{w^{\prime} \chi_{v}^{\prime}}\right) .
\end{aligned}
$$

Finally, the obtained expression for $\overline{w^{\prime} r_{c}^{\prime}}$ is substituted into Eq. (1), which yields Eq. (5). 
Acknowledgements. The research leading to these results has received funding from the European Community's Seventh Framework Programme (FP7/2007-2013) in the InGOS project under grant agreement no. 284274. O. Peltola is grateful to the Magnus Ehrnrooth foundation for funding. COST Action ES0804 is acknowledged for funding a short-term scientific mission to the Netherlands. We are grateful to the Academy of Finland Centre of Excellence programme (project no. 272041), ICOS (271878), ICOS-Finland (281255) and ICOS-ERIC (281250) for funding part of this research. Also, the Nordic Center of Excellence DEFROST, ESF TTORCH Research Networking Programme and EU project GHG-LAKE are acknowledged. Furthermore, Picarro Inc. and Gloria Jacobson are acknowledged for lending the G2311-f instrument and for valuable discussion during the preparation of this study.

\section{Edited by: L. Merbold}

\section{References}

Beljaars, A. C. M. and Bosveld, F. C.: Cabauw data for the validation of land surface parameterization schemes, J. Climate, 10, 1172-119, 1997.

Bousquet, P., Ciais, P., Miller, J. B., Dlugokencky, E. J., Hauglustaine, D. A., Prigent, C., Van der Werf, G. R., Peylin, P., Brunke, E.-G., Carouge, C., Langenfelds, R. L., Lathière, J., Papa, F., Ramonet, M., Schmidt, M., Steele, L. P., Tyler, S. C., and White, J.: Contribution of anthropogenic and natural sources to atmospheric methane variability, Nature 443, 439-443, 2006.

Businger, J. A.: Evaluation of the Accuracy with which Dry Deposition can be Measured with Current Micrometeorological Techniques, J. Clim. Appl. Meteorol., 25, 1100-1124, doi:10.1175/1520-0450(1986)025<1100:EOTAWW>2.0.CO;2, 1986.

Chen, H., Winderlich, J., Gerbig, C., Hoefer, A., Rella, C. W., Crosson, E. R., Van Pelt, A. D., Steinbach, J., Kolle, O., Beck, V., Daube, B. C., Gottlieb, E. W., Chow, V. Y., Santoni, G. W., and Wofsy, S. C.: High-accuracy continuous airborne measurements of greenhouse gases $\left(\mathrm{CO}_{2}\right.$ and $\left.\mathrm{CH}_{4}\right)$ using the cavity ringdown spectroscopy (CRDS) technique, Atmos. Meas. Tech., 3, 375-386, doi:10.5194/amt-3-375-2010, 2010.

Ciais, P., Sabine, C., Bala, G., Bopp, L., Brovkin, V., Canadell, J., Chhabra, A., DeFries, R., Galloway, J., Heimann, M., Jones, C., Le Quéré, C., Myneni, R. B., Piao, S., and Thornton, P.: Carbon and Other Biogeochemical Cycles, in: Climate Change 2013: The Physical Science Basis. Contribution of Working Group I to the Fifth Assessment Report of the Intergovernmental Panel on Climate Change, edited by: Stocker, T. F., Qin, D., Plattner, G.K., Tignor, M., Allen, S. K., Boschung, J., Nauels, A., Xia, Y., Bex, V. and Midgley, P. M., Cambridge University Press, Cambridge, United Kingdom and New York, NY, USA, 465-570, 2013.

Detto, M., Verfaillie, J., Anderson, F., Xu, L., and Baldocchi, D.: Comparing laser-based open- and closed-path gas analyzers to measure methane fluxes using the eddy covariance method, Agr. Forest Meteorol., 151, 1312-1324, doi:10.1016/j.agrformet.2011.05.014, 2011.
Dlugokencky, E. J., Steele, L. P., Lang, P. M., and Masarie, K. A.: The growth rate and distribution of atmospheric methane, J. Geophys. Res., 99, 17021-17043, doi:10.1029/94JD01245, 1994.

Dlugokencky, E. J., Nisbet, E. G., Fisher, R., and Lowry, D.: Global atmospheric methane: budget, changes and dangers, Philos. T. R. Soc. A, 369, 2058-2072, doi:10.1098/rsta.2010.0341, 2011.

Eugster, W. and Senn, W.: A Cospectral Correction Model for Measurement of Turbulent $\mathrm{NO}_{2}$ Flux, Bound.-Layer Meteorol., 74, 321-340, doi:10.1007/BF00712375, 1995.

Finkelstein, P. and Sims, P.: Sampling error in eddy correlation flux measurements, J. Geophys. Res.-Atmos., 106, 3503-3509, doi:10.1029/2000JD900731, 2001.

Foken, T. and Wichura, B.: Tools for quality assessment of surfacebased flux measurements, Agr. Forest Meteorol., 78, 83-105, 1996.

Fowler, D., Hargreaves, K. J., Skiba, U., Milne, R., Zahniser, M. S., Moncrieff, J. B., Beverland, I. J. and Gallagher, M. W.: Measurements of $\mathrm{CH}_{4}$ and $\mathrm{N}_{2} \mathrm{O}$ fluxes at the landscape scale using micrometeorological methods, Philos. T. R. Soc. Lond., 351, 339 356, 1995.

Fratini, F., Ibrom, A., Arriga, N., Burba, G., and Papale, D.: Relative humidity effects of water vapour fluxes measured with closedpath eddy-covariance systems with short sampling lines, Agr. Forest Meteorol., 165, 53-63, 2012.

Heimann, M.: Atmospheric science: Enigma of the recent methane budget, Nature, 476, 157-158, 2011.

Hiller, R. V., Zellweger, C., Knohl, A., and Eugster, W.: Flux correction for closed-path laser spectrometers without internal water vapor measurements, Atmos. Meas. Tech. Discuss., 5, 351-384, doi:10.5194/amtd-5-351-2012, 2012.

Ibrom, A., Dellwik, E., Flyvbjerg, H., Jensen, N. O., and Pilegaard, K.: Strong low-pass filtering effects on water vapour flux measurements with closed-path eddy correlation systems, Agr. Forest Meteorol., 147, 140-156, doi:10.1016/j.agrformet.2007.07.007, 2007a.

Ibrom, A., Dellwik, E., Larsen, S. E., and Pilegaard, K.: On the use of the Webb-Pearman-Leuning theory for closedpath eddy correlation measurements, Tellus B., 59, 937-946, doi:10.1111/j.1600-0889.2007.00311.x, 2007b.

Kroon, P. S., Hensen, A., Jonker, H. J. J., Ouwersloot, H. G., Vermeulen, A. T., and Bosveld, F. C.: Uncertainties in eddy covariance flux measurements assessed from $\mathrm{CH}_{4}$ and $\mathrm{N}_{2} \mathrm{O}$ observations, Agr. Forest Meteorol., 150, 806-816, doi:10.1016/j.agrformet.2009.08.008, 2010.

Lenschow, D., Wulfmeyer, V., and Senff, C.: Measuring second- through fourth-order moments in noisy data, J. Atmos. Ocean. Technol., 17, 1330-1347, doi:10.1175/15200426(2000)017<1330:MSTFOM>2.0.CO;2, 2000.

Mammarella, I., Launiainen, S., Gronholm, T., Keronen, P., Pumpanen, J., Rannik, Ü., and Vesala, T.: Relative Humidity Effect on the High-Frequency Attenuation of Water Vapor Flux Measured by a Closed-Path Eddy Covariance System, J. Atmos. Ocean. Technol., 26, 1856-1866, doi:10.1175/2009JTECHA1179.1, 2009.

Massman, W. J.: Concerning the measurement of atmospheric trace gas fluxes with open- and closed-path eddy covariance system: the WPL terms and spectral attenuation., in: Handbook of Micrometeorology, edited by: Lee, X., Massman, W. J., and Law, B., Kluwer Academic Publishers, 133-160, 2004. 
Massman, W. J. and Ibrom, A.: Attenuation of concentration fluctuations of water vapor and other trace gases in turbulent tube flow, Atmos. Chem. Phys., 8, 6245-6259, doi:10.5194/acp-86245-2008, 2008.

Massman, W. J. and Tuovinen, J.-P.: An analysis and implications of alternative methods of deriving the density (WPL) terms for eddy covariance flux measurements, Bound.-Layer Meteorol., 121, 221-227, doi:10.1007/s10546-006-9070-8, 2006.

Mauder, M., Cuntz, M., Druee, C., Graf, A., Rebmann, C., Schmid, H. P., Schmidt, M., and Steinbrecher, R.: A strategy for quality and uncertainty assessment of long-term eddycovariance measurements, Agr. Forest Meteorol., 169, 122-135, doi:10.1016/j.agrformet.2012.09.006, 2013.

McDermitt, D., Burba, G., Xu, L., Anderson, T., Komissarov, A., Riensche, B., Schedlbauer, J., Starr, G., Zona, D., Oechel, W., Oberbauer, S., and Hastings, S.: A new low-power, open-path instrument for measuring methane flux by eddy covariance, Appl. Phys., 102, 391-405, 2010.

Monteil, G., Houweling, S., Dlugockenky, E. J., Maenhout, G., Vaughn, B. H., White, J. W. C., and Rockmann, T.: Interpreting methane variations in the past two decades using measurements of $\mathrm{CH}_{4}$ mixing ratio and isotopic composition, Atmos. Chem. Phys., 11, 9141-9153, doi:10.5194/acp-11-9141-2011, 2011.

Myhre, G., Shindell, D., Bréon, F.-M., Collins, W., Fuglestvedt, J., Huang, J., Koch, D., Lamarque, J.-F., Lee, D., Mendoza, B., Nakajima, T., Robock, A., Stephens, G., Takemura, T. and Zhang, H.: Anthropogenic and Natural Radiative Forcing, in: Climate Change 2013: The Physical Science Basis. Contribution of Working Group I to the Fifth Assessment Report of the Intergovernmental Panel on Climate Change, edited by: Stocker, T. F., Qin, D., Plattner, G.-K., Tignor, M., Allen, S. K., Boschung, J., Nauels, A., Xia, Y., Bex, V. and Midgley, P. M., Cambridge University Press, Cambridge, United Kingdom and New York, NY, USA, 659-740, 2013.

Nara, H., Tanimoto, H., Tohjima, Y., Mukai, H., Nojiri, Y., Katsumata, K., and Rella, C. W.: Effect of air composition $\left(\mathrm{N}_{2}, \mathrm{O}_{2}, \mathrm{Ar}\right.$, and $\mathrm{H}_{2} \mathrm{O}$ ) on $\mathrm{CO}_{2}$ and $\mathrm{CH}_{4}$ measurement by wavelength-scanned cavity ring-down spectroscopy: calibration and measurement strategy, Atmos. Meas. Tech., 5, 2689-2701, doi:10.5194/amt-5-2689-2012, 2012.

Neftel, A., Ammann, C., Fischer, C., Spirig, C., Conen, F., Emmenegger, L., Tuzson, B., and Wahlen, S.: $\mathrm{N}_{2} \mathrm{O}$ exchange over managed grassland: Application of a quantum cascade laser spectrometer for micrometeorological flux measurements, Agr. Forest Meteorol., 150, 775-785, doi:10.1016/j.agrformet.2009.07.013, 2010.

Nisbet, E. G., Dlugokencky, E. J., and Bousquet, P.: Methane on the Rise-Again, Science, 343, 493-495, doi:10.1126/science.1247828, 2014.

Nordbo, A., Kekäläinen, P., Siivola, E., Lehto, R., Vesala, T., and Timonen, J.: Tube transport of water vapor with condensation and desorption, Appl. Phys. Lett., 102, 194101, doi:10.1063/1.4804639, 2013.
Peltola, O., Mammarella, I., Haapanala, S., Burba, G., and Vesala, T.: Field intercomparison of four methane gas analyzers suitable for eddy covariance flux measurements, Biogeosciences, 10 , 3749-3765, doi:10.5194/bg-10-3749-2013, 2013.

Querino, C. A. S., Smeets, C. J. P. P., Vigano, I., Holzinger, R., Moura, V., Gatti, L. V., Martinewski, A., Manzi, A. O., de Araújo, A. C., and Röckmann, T.: Methane flux, vertical gradient and mixing ratio measurements in a tropical forest, Atmos. Chem. Phys., 11, 7943-7953, doi:10.5194/acp-11-79432011, 2011.

Rannik, Ü. and Vesala, T.: Autoregressive filtering versus linear detrending in estimation of fluxes by the eddy covariance method, Bound.-Lay. Meteorol., 91, 259-280, 1999.

Rebmann, C., Kolle, O., Heinesch, B., Queck, R., Ibrom, A., and Aubinet, M.: Data Acquisition and Flux Calculations, in: Eddy Covariance: A Practical Guide to Measurement and Data Analysis, edited by: Aubinet, M., Vesala, T. and Papale, D., Springer Atmospheric Sciences, 59-84, 2012.

Rella, C. W.: Accurate Greenhouse Gas Measurements in $\mathrm{Hu}-$ mid Gas Streams Using the Picarro G1301 Carbon Dioxide/Methane/Water Vapor Gas Analyzer, Tech. rep., 2010.

Rella, C. W., Chen, H., Andrews, A. E., Filges, A., Gerbig, C., Hatakka, J., Karion, A., Miles, N. L., Richardson, S. J., Steinbacher, M., Sweeney, C., Wastine, B., and Zellweger, C.: High accuracy measurements of dry mole fractions of carbon dioxide and methane in humid air, Atmos. Meas. Tech., 6, 837-860, doi:10.5194/amt-6-837-2013, 2013.

Runkle, B. R. K., Wille, C., Gažovič, M., and Kutzbach, L.: Attenuation Correction Procedures for Water Vapour Fluxes from Closed-Path Eddy-Covariance Systems, Bound.-Lay. Meteorol., 142, 401-423, doi:10.1007/s10546-011-9689-y, 2012.

Smeets, C. J. P. P., Holzinger, R., Vigano, I., Goldstein, A. H., and Röckmann, T.: Eddy covariance methane measurements at a Ponderosa pine plantation in California, Atmos. Chem. Phys., 9, 8365-8375, doi:10.5194/acp-9-8365-2009, 2009.

Tuzson, B., Hiller, R. V., Zeyer, K., Eugster, W., Neftel, A., Ammann, C., and Emmenegger, L.: Field intercomparison of two optical analyzers for $\mathrm{CH}_{4}$ eddy covariance flux measurements, Atmos. Meas. Tech., 3, 1519-1531, doi:10.5194/amt-3-1519-2010, 2010.

van Ulden, A. P. and Wieringa, J.: Atmospheric boundary layer research at Cabauw, Bound.-Lay. Meteorol., 78, 39-69, 1996.

Webb, E. K., Pearman, G. I., and Leuning, R.: Correction of Flux Measurements for Density Effects due to Heat and Water-Vapor Transfer, Q. J. R. Meteorol. Soc., 106, 85-100, 1980.

Wienhold, F. G., Welling, M., and Harris, G. W.: Micrometeorological Measurement and Source Region Analysis of Nitrous-Oxide Fluxes from an Agricultural Soil, Atmos. Environ., 29, 22192227, doi:10.1016/1352-2310(95)00165-U, 1995. 